\title{
O gênero Nitzschia (Bacillariaceae) em ambientes lacustres na Planície Costeira do Rio Grande do Sul, Brasil ${ }^{1}$
}

The genus Nitzschia (Bacillariaceae) in lacustrine environments of the Coastal Plain of Rio Grande do Sul State, Brazil ${ }^{I}$

Daniela Bes ${ }^{2} \&$ Lezilda Carvalho Torgan ${ }^{3}$

\begin{abstract}
Resumo
O estudo taxonômico sobre o gênero Nitzschia Hassall, nas áreas da Lagoa do Casamento e do Butiazal de Tapes, localizados entre $30^{\circ} 40^{\prime}-30^{\circ} 10^{\prime} \mathrm{S}$ e $50^{\circ} 30^{\prime}-51^{\circ} 30^{\prime} \mathrm{W}$, baseou-se em amostras de plâncton e metafiton, coletadas em 21 estações abrangendo diferentes ambientes (lagoas interligadas, lagoas isoladas, banhados e açude) no outono e primavera de 2003. Foram encontrados 35 táxons específicos e infra-específicos, destacando-se 11 novas ocorrências para o Estado e cinco para a Planície Costeira do Rio Grande do Sul. Quanto ao hábito, 91\% dos táxons ocorreram no plâncton e metafiton e 9\% restringiram-se ao metafiton. A área da Lagoa do Casamento apresentou maior riqueza (35 táxons) em relação à área do Butiazal de Tapes (13 táxons), provavelmente pela presença de ambientes em conexão com a laguna dos Patos, a qual detém uma flora rica de Nitzschia, associado às condições de alta condutividade e pH da água. São apresentadas descrições, ilustrações e comentários sobre as variações morfológicas e/ou métricas dos táxons.

Palavras-chave: diatomáceas, morfologia, taxonomia
\end{abstract}

\begin{abstract}
The taxonomic study about the genus Nitzschia Hassall, the Lagoon Casamento and Butiazal de Tapes areas, located at $30^{\circ} 40^{\prime}-30^{\circ} 10^{\prime} \mathrm{S}$ e $50^{\circ} 30^{\prime}-51^{\circ} 30^{\prime} \mathrm{W}$, was based in plankton and metaphyton samples, collected in 21 stations including different environments (interconnected lakes, isolated lakes, swamps and ponds), in the fall and spring of 2003. The results revealed the presence of 35 taxa specific and infra-specific, highlighting 11 new records for the State and 5 new ones for the Coastal Plains of Rio Grande do Sul. Regarding the habit and $91 \%$ occurred in plankton and metaphyton, only $9 \%$ were restricted to metaphyton. The Lagoon do Casamento area presented greater richness (35 taxa) compared to the Butiazal de Tapes area (13 taxa), probably due to the presence of environments in connection with the Patos lagoon, that has a rich flora of Nitzschia, associated to a high conductivity and water $\mathrm{pH}$ conditions. Descriptions, illustrations and comments about the morphological and/or metric variations and of the taxa are presented.
\end{abstract}

Key words: diatoms, morphology, taxonomy.

\section{Introdução}

A família Bacillariaceae Ehrenberg é composta por 20 gêneros, sendo Nitzschia Hassall o mais representativo, com atualmente 323 espécies descritas e aceitas taxonomicamente (Guiry \& Guiry 2010).

No Brasil, estudos sobre o gênero Nitzschia foram realizados, principalmente, na Região Sul. Para os ambientes continentais do estado do Paraná, Tremarin et al. (2009) citam 63 táxons específicos e infraespecíficos e para a região costeira de Santa Catarina
Moreira-Filho et al. (1985) listam 15 espécies e três variedades taxonômicas. No Rio Grande do Sul, 68 espécies e 16 variedades do gênero são referidas, as quais se encontram distribuídas nos mais variados ambientes aquáticos, principalmente na Depressão Central (Torgan et al. 1999). Já para a Planície Costeira do Rio Grande do Sul, o conhecimento sobre este gênero é limitado. Para o litoral Norte existem os trabalhos de Busellato \& Aguiar (1979), Callegaro (1981), Garcia e Vélez (1995), Salomoni (1997) e

\footnotetext{
Parte da dissertação de Mestrado da primeira autora, Programa de Pós-Graduação em Botânica da Universidade Federal do Rio Grande do Sul.

${ }^{2}$ Universidade do Rio Grande do Sul, Programa de Pós-graduação em Botânica, Av. Bento Gonçalves 9500, Campus do Vale, 91501-970, Porto Alegre, RS, Brasil. danielabes@yahoo.com.br.Bolsista CNPq-Mestrado.

${ }^{3}$ Fundação Zoobotânica do Rio Grande do Sul, Museu de Ciências Naturais, R. Dr. Salvador França 1427, 90690-000, Porto Alegre, RS, Brasil. lezilda.torgan@fzb.rs.gov.br.
} 
Cardoso \& Motta-Marques (2003, 2004). Nestes, as espécies encontram-se brevemente descritas ou apenas listadas. Para o litoral Sul, os trabalhos existentes são os de Callegaro \& Salomoni (1988), com apenas duas espécies e o de Lobo et al. (1994) que lista 24 táxons.

Sendo assim, esta pesquisa teve por objetivos realizar um estudo detalhado sobre o gênero Nitzschia, apresentando descrição e comentários sobre as variações métricas e morfológicas das espécies. A riqueza e a distribuição dos táxons nos diferentes sistemas lacustres são também apresentadas.

\section{Material e Métodos}

As amostragens foram efetuadas nas áreas da Lagoa do Casamento e do Butiazal de Tapes localizados, entre $30^{\circ} 40^{\prime}-30^{\circ} 10^{\prime} \mathrm{S}$ e $50^{\circ} 30^{\prime}-51^{\circ} 30^{\prime} \mathrm{W}$, adjacentes às margens da laguna dos Patos, Rio Grande do Sul (Fig. 1). Estas foram realizadas em 21 estações georreferenciadas (Tab. 1), abrangendo diferentes ambientes lacustres (lagoas isoladas, lagoas interligadas, banhados e açude) em duas épocas do ano: outono (maio e junho de 2003) e primavera (outubro a dezembro de 2003).

Um total de 87 amostras foi obtido, sendo as de plâncton coletadas com frascos na sub-superfície da água e as de metafíton coletadas através de espremido manual de macrófitas aquáticas, nas zonas pelágica e litorânea dos corpos d'água. Utilizou-se como fixador formaldeído e solução de Transeau (Bicudo \& Bicudo 1970), respectivamente. Para a remoção da matéria orgânica das amostras e limpeza das frústulas utilizouse a técnica de Simonsen (1974). As lâminas permanentes foram confeccionadas utilizando-se a resina Naphrax como meio de montagem para a observação em microscópio óptico (MO). Parte do material foi colocado em lâminas de raios-X sob stubs de alumínio para a observação em microscópio eletrônico de varredura (MEV).

Seguiu-se o sistema de Round et al. (1990) para o enquadramento taxonômico do gênero. $\mathrm{O}$ material encontra-se depositado no Herbário Prof. Dr. Alarich Schultz (HAS), na Fundação Zoobotânica do Rio Grande do Sul (Tab. 2). Simultaneamente, foram efetuadas medições pontuais de condutividade e $\mathrm{pH}$, através dos aparelhos marca HACH modelos 50150 e 50050.

Para avaliar a similaridade entre as duas áreas, os ambientes foram agrupados em função da presença ou ausência específica dos táxons, utilizando TWINSPAN - Análise de Espécies Indicadoras de Dupla Entrada (Hill 1979), processadas no software PC-ORD, versão 4.0 para Windows (McCune \& Mefford 1999). A análise seguiu a configuração padrão (Níveis de corte de pseudoespécie: 0 - presença e ausência; tamanho mínimo do grupo para divisão: 5; número máximo de indicadores por divisão: 5; número máximo de espécies na tabela final: 200; nível máximo de divisões: 6).

\section{Resultados e Discussão}

\section{Táxons identificados}

O estudo do gênero Nitzschia em ambientes lacustres na Planície Costeira do estado Rio Grande do Sul revelou a presença de 35 táxons.

1. Nitzschia acicularis var. major $O$. Müller, Bot. Jahrb. 36: 177, pl 2, fig. 13, 14. $1909 . \quad$ Fig. 2 a-b

Valvas linear-lanceoladas, extremidades afiladas arredondadas, fíbulas equidistantes, estrias inconspícuas em MO. Medidas: 93-106 $\mu \mathrm{m}$ de comprimento, 4-5 $\mu \mathrm{m}$ de largura, 11-13 fíbulas em $10 \mu \mathrm{m}$.

Lâminas examinadas: 5771, 6008, 6016.

Os indivíduos observados assemelham-se morfologicamente ao material tipo encontrado no plâncton do lago Nyassa (África) por Müller (1909), diferindo somente no número de fíbulas (16 em $10 \mu \mathrm{m})$. Posteriormente, Guermeur (1954), no estudo das diatomáceas do lago Tamma (África), encontrou este táxon com número de fíbulas semelhantes ao observado (12-14 fíbulas em $10 \mu \mathrm{m})$. Esta espécie difere de Nitzschia graciliformis Lange-Bert. \& Simonsen por apresentar maior espaçamento central das fíbulas e possuir menor largura $(2-2,5 \mu \mathrm{m})$.

2. Nitzschia agnita Hust., Ab. Natur. Ver. Bremen 34: 347, fig. 51. 1957.

Fig. 2 c-d

Valvas linear-lanceoladas, extremidades atenuadas, subcapitado-rostradas, fíbulas equidistantes, estrias inconspícuas em MO. Medidas: $16-18 \mu \mathrm{m}$ de comprimento, $3 \mu \mathrm{m}$ de largura, $21-23$ fíbulas em $10 \mu \mathrm{m}$. Lâmina examinada: 5999.

A descrição original de Hustedt (1957) apresenta as dimensões de um único indivíduo com $33 \mu \mathrm{m}$ de comprimento, $3,5 \mu \mathrm{m}$ de largura, 18 fíbulas em $10 \mu \mathrm{m})$. O material observado apresenta menores dimensões e maior número de fíbulas, enquanto as demais características concordam com a diagnose da espécie. Krammer \& Lange-Bertalot (1988), no estudo da flora da Europa, mencionam somente os valores de densidade de estrias $(35 \mathrm{em} 10 \mu \mathrm{m})$. Este táxon difere de Nitzschia fonticola Grun., pois esta apresenta menor densidade de fíbulas em $10 \mu \mathrm{m}$ (12-15) e possui estrias conspícuas. 


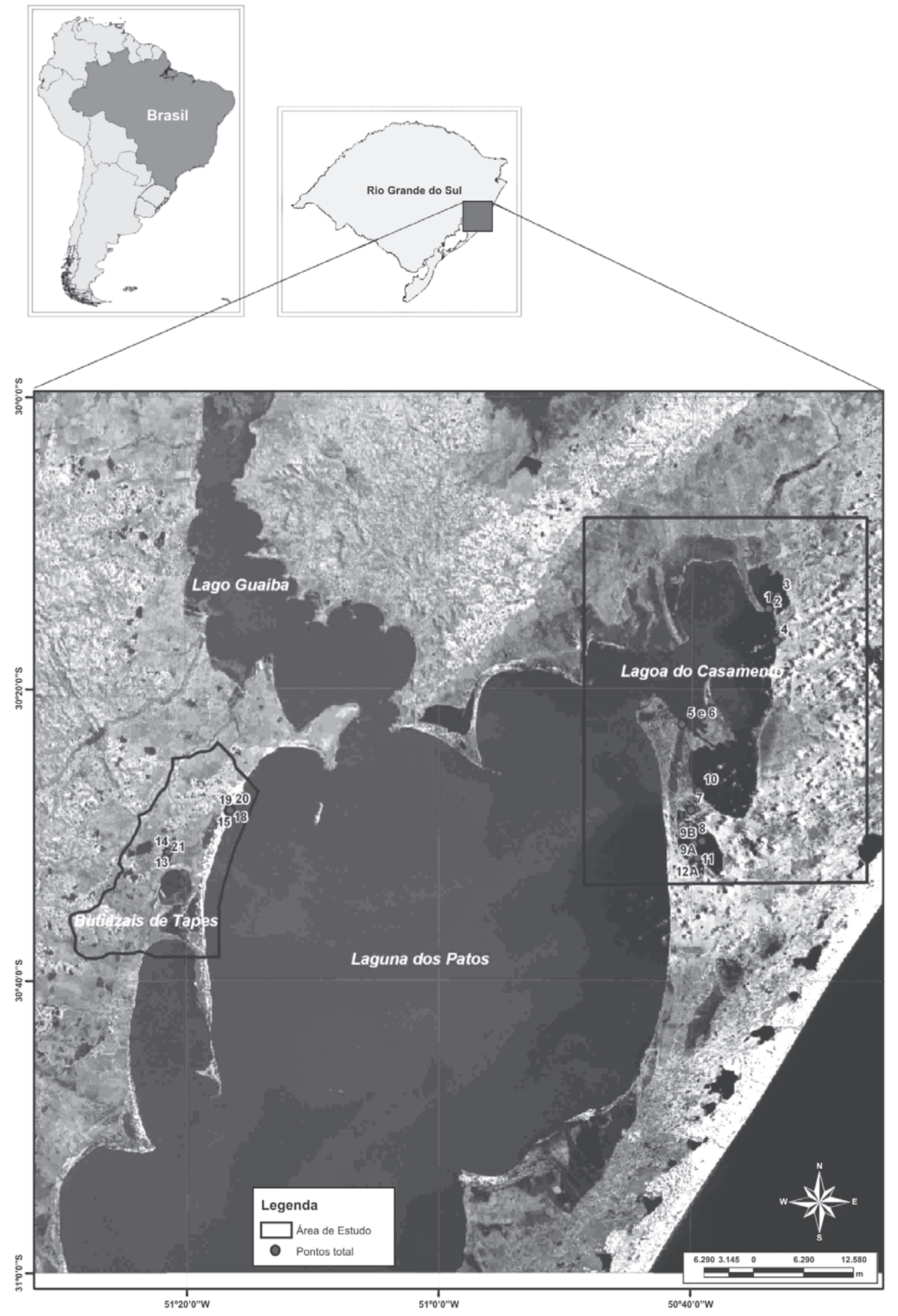

Figura 1 - Mapa das áreas de estudo e das estações de amostragem. Estações 1-12: Área da Lagoa do Casamento; estações 13-21: Área do Butiazal de Tapes.

Figure 1 - Areas of study and sampling stations map. Stations 1-12: Lake Casamento area; stations 13-21: Butiazal Tapes area. 
Tabela 1 - Relação das estações e ambientes amostrados nas áreas da Lagoa do Casamento (LC) e Butiazal de Tapes (BT), com as referências das coordenadas geográficas e dos municípios.

Table 1 - List of the stations and environments sampled in the Lagoa do Casamento (LC) and Butiazal de Tapes (BT) areas, with the geographic coordinates and municipality references.

\begin{tabular}{|c|c|c|c|c|}
\hline$\overline{\text { Estações }}$ & Áreas & Ambientes & Coordenadas Geográficas & Municípios \\
\hline 1 & $\mathrm{LC}$ & Banhado entre lagoa Capivari e Casamento & $30^{\circ} 14^{\prime} 29^{\prime \prime} \mathrm{S} 50^{\circ} 33^{\prime} 55^{\prime \prime} \mathrm{W}$ & Capivari do Sul \\
\hline 2 & $\mathrm{LC}$ & Banhado entre lagoa Capivari e Casamento & $30^{\circ} 14^{\prime} 32^{\prime \prime} \mathrm{S} 50^{\circ} 33^{\prime} 59^{\prime \prime} \mathrm{W}$ & Capivari do Sul \\
\hline 3 & $\mathrm{LC}$ & Lagoa Capivari & $30^{\circ} 14^{\prime} 38^{\prime \prime} \mathrm{S} 50^{\circ} 33^{\prime} 15^{\prime \prime} \mathrm{W}$ & Capivari do Sul \\
\hline 4 & $\mathrm{LC}$ & Lagoa do Casamento & $30^{\circ} 16^{\prime} 40^{\prime \prime} \mathrm{S} 50^{\circ} 33^{\prime} 25^{\prime \prime} \mathrm{W}$ & Palmares do Sul \\
\hline $4 \mathrm{~A}$ & $\mathrm{LC}$ & Banhado Ilha Grande & - & Palmares do Sul \\
\hline 5 & $\mathrm{LC}$ & Banhado Fazenda Rincão Anastácio & $30^{\circ} 22^{\prime} 26^{\prime \prime} \mathrm{S} 50^{\circ} 40^{\prime} 48^{\prime \prime} \mathrm{W}$ & Palmares do Sul \\
\hline 6 & $\mathrm{LC}$ & Banhado Fazenda Rincão Anastácio & $30^{\circ} 22^{\prime} 26^{\prime \prime} \mathrm{S} 50^{\circ} 40^{\prime} 48^{\prime \prime} \mathrm{W}$ & Palmares do Sul \\
\hline 7 & $\mathrm{LC}$ & Lagoa dos Gateados - norte & $30^{\circ} 28^{\prime} 18^{\prime \prime} \mathrm{S} 50^{\circ} 40^{\prime} 4^{\prime \prime} \mathrm{W}$ & Palmares do Sul/Mostardas \\
\hline 8 & $\mathrm{LC}$ & Lagoa dos Gateados - norte & $30^{\circ} 30^{\prime} 19^{\prime \prime} \mathrm{S} 50^{\circ} 39^{\prime} 50^{\prime \prime} \mathrm{W}$ & Palmares do Sul/Mostardas \\
\hline $9 \mathrm{~A}$ & $\mathrm{LC}$ & Lagoa dos Gateados - norte & $30^{\circ} 30^{\prime} 26^{\prime \prime} \mathrm{S} 50^{\circ} 39^{\prime} 12^{\prime \prime} \mathrm{W}$ & Palmares do Sul/Mostardas \\
\hline 9B & $\mathrm{LC}$ & Lagoa dos Gateados - norte & $30^{\circ} 30^{\prime} 39^{\prime \prime} \mathrm{S} 50^{\circ} 39^{\prime} 49^{\prime \prime} \mathrm{W}$ & Palmares do Sul/Mostardas \\
\hline 10 & $\mathrm{LC}$ & Canal do Sangradouro & $30^{\circ} 26^{\prime} 60^{\prime \prime} \mathrm{S} 50^{\circ} 39^{\prime} 29^{\prime \prime} \mathrm{W}$ & Palmares do Sul \\
\hline 11 & $\mathrm{LC}$ & Lagoa dos Gateados - sul & $30^{\circ} 32^{\prime} 8^{\prime \prime S} 50^{\circ} 39^{\prime} 39^{\prime \prime} \mathrm{W}$ & Mostardas \\
\hline $12 \mathrm{~A}$ & $\mathrm{LC}$ & Lagoa dos Gateados - sul & $30^{\circ} 31^{\prime} 34^{\prime \prime} \mathrm{S} 50^{\circ} 39^{\prime} 33^{\prime \prime} \mathrm{W}$ & Mostardas \\
\hline $12 \mathrm{~B}$ & $\mathrm{LC}$ & Lagoa dos Gateados - sul & $30^{\circ} 31^{\prime} 29^{\prime \prime} \mathrm{S} 50^{\circ} 38^{\prime} 37^{\prime \prime} \mathrm{W}$ & Tapes \\
\hline 13 & B T & Lagoa Charutão & $30^{\circ} 30^{\prime} 58^{\prime \prime} \mathrm{S} 51^{\circ} 21^{\prime} 17^{\prime \prime} \mathrm{W}$ & Tapes \\
\hline 14 & B T & Lagoa Charutão & $30^{\circ} 31^{\prime} 14^{\prime \prime} \mathrm{S} 51^{\circ} 21^{\prime} 25^{\prime \prime} \mathrm{W}$ & Tapes \\
\hline 15 & B T & Açude Fazenda São Miguel & $30^{\circ} 31^{\prime} 7^{\prime \prime S} 51^{\circ} 22^{\prime} 23^{\prime \prime} \mathrm{W}$ & Tapes \\
\hline 16 & B T & Lagoa das Capivaras & $30^{\circ} 28^{\prime} 11^{\prime \prime} \mathrm{S} 51^{\circ} 16^{\prime} 30^{\prime \prime} \mathrm{W}$ & Tapes \\
\hline 17 & $\mathrm{~B} \mathrm{~T}$ & Lagoa das Capivaras & $30^{\circ} 28^{\prime} 11^{\prime \prime} \mathrm{S} 51^{\circ} 16^{\prime} 30^{\prime \prime} \mathrm{W}$ & Tapes \\
\hline 18 & B T & Banhado com Sphagnum & $30^{\circ} 28^{\prime} 24^{\prime \prime} \mathrm{S} 51^{\circ} 16^{\prime} 38^{\prime \prime} \mathrm{W}$ & Tapes \\
\hline 19 & B T & Lagoinha entre dunas & $30^{\circ} 28^{\prime} 25^{\prime \prime} \mathrm{S} 51^{\circ} 16^{\prime} 36^{\prime \prime} \mathrm{W}$ & Tapes \\
\hline 20 & B T & Banhado entre dunas & $30^{\circ} 28^{\prime} 20^{\prime \prime} \mathrm{S} 51^{\circ} 16^{\prime} 30^{\prime \prime} \mathrm{W}$ & Tapes \\
\hline 21 & B T & Lagoa Redonda & $30^{\circ} 31^{\prime} 36^{\prime \prime} \mathrm{S} 51^{\circ} 21^{\prime} 34^{\prime \prime} \mathrm{W}$ & Tapes \\
\hline
\end{tabular}

Tabela 2 - Números das amostras e das lâminas permanentes registradas no Herbário Prof. Dr. Alarich R. H. Schultz (HAS), data e tipo de amostra ( $\mathrm{P}=$ plâncton e $\mathrm{M}=$ metafíton), local de amostragem e nome do coletor.

Table 2 - Numbers of the samples and the permanent slides registered at the Herbarium Prof. Dr. R. Alarich H. Schultz (HAS), date and type of sample ( $\mathrm{P}=$ plankton and $\mathrm{M}=$ metaphyton), sampling sites and collectors names.

\begin{tabular}{|c|c|c|c|c|c|}
\hline $\mathrm{N}^{0}$ de Registro & Lâminas & Data & Tipo & Local & Coletor \\
\hline HAS 104092 & 5808,5809 & $05 / 05 / 2003$ & $\mathrm{P}$ & Banhado entre lagoa Capivari e Casamento & Werner, V.R. \\
\hline HAS 104096 & 5811 & $05 / 05 / 2003$ & M & Banhado entre lagoa Capivari e Casamento & Werner, V.R. \\
\hline HAS 104101 & 5764 & $05 / 05 / 2003$ & $\mathrm{P}$ & Lagoa Capivari & Torgan, L.C. \\
\hline HAS 104117 & 5973 & $07 / 05 / 2003$ & M & Lagoa do Casamento & Torgan, L.C. \\
\hline HAS 104121 & 5813,5814 & $07 / 05 / 2003$ & M & Banhado Fazenda Rincão Anastácio & Werner, V.R. \\
\hline HAS 104123 & 5783,5789 & $07 / 05 / 2003$ & $\mathrm{P}$ & Banhado Fazenda Rincão Anastácio & Werner, V.R. \\
\hline HAS 104124 & 5975 & $07 / 05 / 2003$ & M & Banhado Fazenda Rincão Anastácio & Werner, V.R. \\
\hline HAS 104133 & 5980 & $07 / 05 / 2003$ & M & Lagoa dos Gateados - norte & Werner, V.R. \\
\hline HAS 104135 & 5779,5785 & $08 / 05 / 2003$ & $\mathrm{P}$ & Lagoa dos Gateados - sul & Werner, V.R. \\
\hline HAS 104139 & 5792 & $08 / 05 / 2003$ & $\mathrm{P}$ & Lagoa dos Gateados - sul & Werner, V.R. \\
\hline HAS 104140 & 5737,5738 & $08 / 05 / 2003$ & M & Lagoa dos Gateados - norte & Werner, V.R. \\
\hline HAS 104144 & 5983 & $08 / 05 / 2003$ & M & Lagoa dos Gateados - norte & Werner, V.R. \\
\hline HAS 104145 & 5984 & $08 / 05 / 2003$ & M & Lagoa dos Gateados - norte & Torgan, L.C. \\
\hline HAS 104147 & 5986 & $08 / 05 / 2003$ & M & Lagoa dos Gateados - norte & Torgan, L.C. \\
\hline HAS 104152 & 5766 & $08 / 05 / 2003$ & $\mathrm{P}$ & Lagoa dos Gateados - norte & Torgan, L.C. \\
\hline HAS 104163 & 5994 & $08 / 05 / 2003$ & $\mathrm{M}$ & Lagoa dos Gateados - norte & Torgan, L.C. \\
\hline
\end{tabular}




\begin{tabular}{|c|c|c|c|c|c|}
\hline $\mathrm{N}^{\circ}$ de Registro & Lâminas & Data & Tipo & Local & Coletor \\
\hline HAS 104176 & 5997 & $09 / 05 / 2003$ & M & Lagoa dos Gateados - sul & Werner, V.R. \\
\hline HAS 104182 & 5999 & $09 / 05 / 2003$ & M & Lagoa dos Gateados - sul & Torgan, L.C. \\
\hline HAS 104183 & 5807 & $09 / 05 / 2003$ & $\mathrm{P}$ & Lagoa dos Gateados - sul & Torgan, L.C. \\
\hline HAS 104193 & 6004 & $09 / 05 / 2003$ & M & Lagoa dos Gateados - sul & Torgan, L.C. \\
\hline HAS 104196 & 5816 & $03 / 06 / 2003$ & $\mathrm{P}$ & Lagoa Charutão & Werner, V.R. \\
\hline HAS 104206 & 5780,5786 & $04 / 06 / 2003$ & $\mathrm{P}$ & Açude Fazenda São Miguel & Werner, V.R. \\
\hline HAS 104207 & 6008 & $04 / 06 / 2003$ & M & Açude Fazenda São Miguel & Torgan, L.C. \\
\hline HAS 104210 & 6010 & $04 / 06 / 2003$ & $\mathrm{P}$ & Lagoa das Capivaras & Werner, V.R. \\
\hline HAS 104212 & 5834-A & $04 / 06 / 2003$ & M & Banhado entre dunas & Werner, V.R. \\
\hline HAS 104215 & 5782 & $04 / 06 / 2003$ & $\mathrm{P}$ & Lagoa das Capivaras & Fritz, R. \\
\hline HAS 104341 & 5771 & $27 / 10 / 2003$ & $\mathrm{P}$ & Banhado entre lagoa Capivari e Casamento & Alves-da-Silva, S. \\
\hline HAS 104342 & 5772 & $27 / 10 / 2003$ & $\mathrm{P}$ & Banhado entre lagoa Capivari e Casamento & Alves-da-Silva, S. \\
\hline HAS 104349 & 5773 & $27 / 10 / 2003$ & $\mathrm{P}$ & Lagoa do Casamento & Alves-da-Silva, $\mathrm{S}$. \\
\hline HAS 104350 & 6014 & $27 / 10 / 2003$ & M & Lagoa do Casamento & Alves-da-Silva, S. \\
\hline HAS 104354 & 5894 & $18 / 11 / 2003$ & $\mathrm{P}$ & Lagoa do Casamento & Cardoso, L. \\
\hline HAS 104358 & 5892 & $19 / 11 / 2003$ & $\mathrm{P}$ & Lagoa do Casamento & Cardoso, L. \\
\hline HAS 104360 & 5844 & $19 / 11 / 2003$ & M & Lagoa do Casamento & Cardoso, L. \\
\hline HAS 104363 & 5774,5775 & $29 / 10 / 2003$ & $\mathrm{P}$ & Banhado Fazenda Rincão Anastácio & Alves-da-Silva, S. \\
\hline HAS 104364 & 5859,6016 & $29 / 10 / 2003$ & M & Banhado Fazenda Rincão Anastácio & Alves-da-Silva, S. \\
\hline HAS 104366 & 5849 & $19 / 11 / 2003$ & M & Lagoa do Casamento & Alves-da-Silva, S. \\
\hline HAS 104367 & 6015 & $29 / 10 / 2003$ & $\mathrm{P}$ & Banhado Fazenda Rincão Anastácio & Alves-da-Silva, S. \\
\hline HAS 104368 & 6018 & $28 / 10 / 2003$ & M & Banhado Fazenda Rincão Anastácio & Alves-da-Silva, $\mathrm{S}$. \\
\hline HAS 104376 & 5850 & $19 / 11 / 2003$ & $\mathrm{P}$ & Lagoa dos Gateados - norte & Cardoso, L. \\
\hline HAS 104386 & 5851,5852 & $19 / 11 / 2003$ & M & Canal Sangradouro & Cardoso, L. \\
\hline HAS 104390 & 5893 & $30 / 10 / 2003$ & $\mathrm{P}$ & Canal Sangradouro & Alves-da-Silva, S. \\
\hline HAS 104392 & 5854,6020 & $30 / 10 / 2003$ & M & Canal Sangradouro & Alves-da-Silva, $\mathrm{S}$. \\
\hline HAS 104393 & 5777 & $31 / 10 / 2003$ & $\mathrm{P}$ & Lagoa dos Gateados - sul & Alves-da-Silva, S. \\
\hline HAS 104396 & 5853 & $29 / 10 / 2003$ & $\mathrm{P}$ & Banhado Ilha Grande & Alves-da-Silva, S. \\
\hline HAS 104403 & 5874 & $31 / 10 / 2003$ & M & Lagoa dos Gateados - sul & Alves-da-Silva, $\mathrm{S}$. \\
\hline HAS 104409 & 5880,6022 & $29 / 10 / 2003$ & $\mathrm{P}$ & Banhado Ilha Grande & Alves-da-Silva, $\mathrm{S}$. \\
\hline HAS 104410 & 6023 & $29 / 10 / 2003$ & M & Banhado Ilha Grande & Alves-da-Silva, S. \\
\hline HAS 104427 & 5848 & $02 / 12 / 2003$ & $\mathrm{P}$ & Açude Fazenda São Miguel & Cardoso, L. \\
\hline HAS 104431 & 5842,5845 & $02 / 12 / 2003$ & M & Açude Fazenda São Miguel & Cardoso, L. \\
\hline HAS 104435 & 5846 & $03 / 12 / 2003$ & M & Lagoa das Capivaras & Cardoso, L. \\
\hline HAS 104440 & 5869 & $03 / 12 / 2003$ & $\mathrm{P}$ & Banhado com Sphagnum & Cardoso, L. \\
\hline HAS 104449 & 5863 & $03 / 12 / 2003$ & M & Banhado entre dunas & Cardoso, L. \\
\hline HAS 104455 & 5867 & $03 / 12 / 2003$ & M & Lagoa Redonda & Cardoso, L. \\
\hline
\end{tabular}

3. Nitzschia brevissima Grun. var. brevissima in Van Heurck, Syn. Diat. Belg., pl. 67, fig. 4. 1881.

Fig. 2 e-n

Valvas lineares com leve constrição mediana, extremidades atenuado-subcapitadas, podendo ser levemente curvadas para lados opostos, fíbulas não equidistantes, estrias inconspícuas em MO. Medidas: $20-57 \mu \mathrm{m}$ de comprimento, $3-5 \mu \mathrm{m}$ de largura, 5-9 fíbulas em $10 \mu \mathrm{m}$.

Lâminas examinadas: 5771, 5772, 5773, 5792, 5807, 5809, 5811, 5813, 5844, 5849, 5851, 5859, 5880, 5892, 5893, 5980, 5997, 5999, 6014, 6016, 6018, 6022, 6023.
O material encontrado é morfologicamente semelhante ao referido por Krammer \& Lange-Bertalot (1988) e Van Heurck (1880-1885). Esta espécie apresenta alta densidade de estrias em $10 \mathrm{~mm}$, por isso tornam-se inconspícuas em microscopia óptica. Krammer \& Lange-Bertalot (1988) apresentam 30-38 estrias para esta espécie e Van Heurck (1880-1885) menciona 30-36 estrias em $10 \mu \mathrm{m}$. Alguns indivíduos observados (Fig. 2 e-n) demonstraram maior relação comprimento/largura em relação ao citado na literatura, porém, estes se enquadram nas demais características do material tipo. Assim, optou-se por deixá-los dentro 


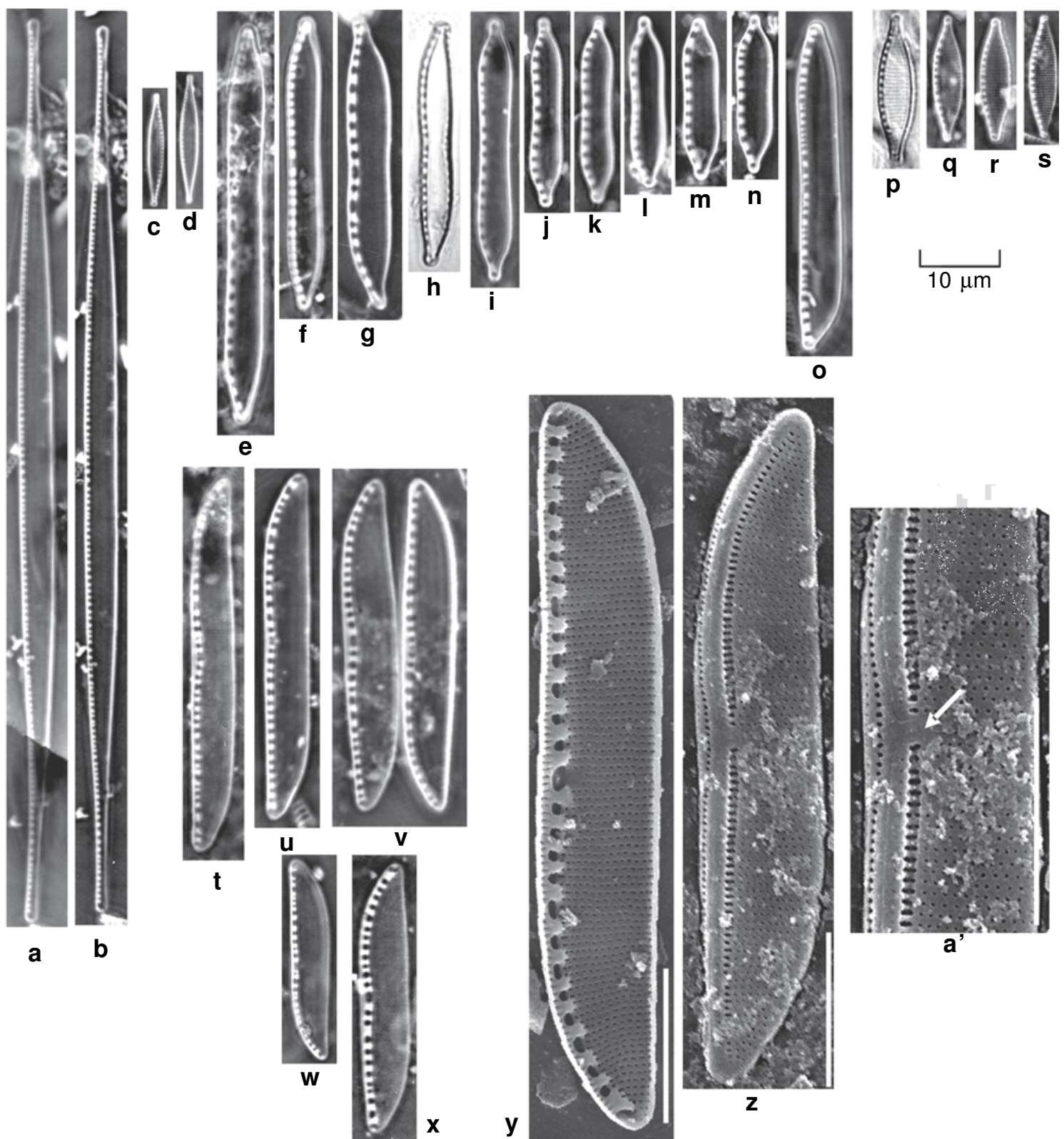

Figura 2 - MO e MEV - a, b. N. acicularis var. major. c-d. $N$. agnita. e-n. N. brevissima var. brevissima. o. $N$. brevissima aff. var. terricola. p-s. N. cf. bryophila. t-a'. N. clausii, MEV - y. vista interna; z. vista externa; a'. detalhe da região central da valva, vista externa. Escala $=10 \mu \mathrm{m}, \mathrm{a}^{\prime}=5 \mu \mathrm{m}$.

Figure 2 - LM and SEM - a, b. $N$. acicularis var. major. c-d. $N$. agnita. e-h. $N$. brevissima var. brevissima. o. $N$. brevissima aff. var. terricola. p-s. N. cf. bryophila. t-a'. N. clausii, SEM - y. internal view; z. external view; a'. detail of the central area of the valve, external view. Scale bars $=10 \mu \mathrm{m}, \mathrm{a}^{\prime}=5 \mu \mathrm{m}$.

desta espécie. Na América do Sul, esta espécie foi encontrada no rio de La Plata, Uruguai (Metzeltin et al. 2005) e no rio das Cruzes, Chile (Rumrich et al. 2000). No Rio Grande do Sul, foi observada anteriormente na represa de Águas Belas em Viamão, no lago Guaíba (Torgan et al. 1999) e no rio Pardinho(Lobo et al. 2004b).
4. Nitzschia brevissima aff. var. terricola (Lund) Ludwig, Estudos de Biologia 20: 3, fig. 1. 1989.

Fig. 20

Valvas lineares com leve constrição mediana, extremidades cuneadas, atenuado-subcapitadas, fíbulas equidistantes, interrompidas por maior 
espaçamento na região central, estrias inconspícuas em MO. Medidas: 22-28 $\mu \mathrm{m}$ de comprimento, 4-5 $\mu \mathrm{m}$ de largura, 6-9 fíbulas em $10 \mu \mathrm{m}$.

Lâminas examinadas: 5772, 5983.

Os espécimes encontrados possuem afinidade aos apresentados por Ludwig (1989), porém, estes possuem maiores dimensões $(42,6$ $48,4 \mu \mathrm{m}$ de comprimento) e contorno valvar mais acentuadamente sigmóide em relação ao material observado. No Rio Grande do Sul, esta variedade foi encontrada na represa Canastra, município de Canela, RS (Raupp et al. 2006).

5. Nitzschia cf. bryophila (Hust.) Hust., Int. Rev. Hydrobiol. Hydrogr. 43: 232, figs 66-71. 1943.

Fig. 2 p-s

Valvas linear-lanceoladas, extremidades capitadas a subcapitadas, fíbulas equidistantes. Medidas: $16-19 \mu$ m de comprimento, $3-5 \mu$ m de largura, 12-14 fíbulas em $10 \mu \mathrm{m}, 25-26$ estrias em $10 \mu \mathrm{m}$.

Lâminas examinadas: 5737, 5785, 5844, 5983, 5999.

Manteve-se a identificação da espécie em conferatum, pois os exemplares observados diferem do material tipo (Hustedt 1943) pela maior largura. Os espécimes da Europa apresentados por Krammer \& Lange-Bertalot (1988) também se diferenciam dos encontrados por possuir maior densidade de estrias (30-32 em $10 \mu \mathrm{m})$ e menor largura $(2-3,5 \mu \mathrm{m})$.

6. Nitzschia clausii Hantsch, Hedwigia 2: 40, pl. 4, fig. 7. 1860.

Fig. 2 t-a'

Valvas lineares, extremidades cuneadoarredondadas, fíbulas equidistantes, interrompidas por maior espaçamento na região central e afastadas da margem, estrias inconspícuas em MO. Em MEV apresenta estrias formadas por uma fileira de aréolas e interrompidas na região central. Rafe com extremidades proximais curvadas para a região mediana das valvas. Fíbulas de tamanhos desiguais, levemente maiores na região central e em uma das extremidades (Fig. 2 y-z). Presença de uma fileira de aréolas alongadas perpendicular à rafe. Possui uma fileira de aréolas no manto (Fig. 2a'). Medidas: 25$45 \mu \mathrm{m}$ de comprimento, 4-6 $\mu \mathrm{m}$ de largura, 10-12 fíbulas em $10 \mu \mathrm{m}, 37-47$ estrias em $10 \mu \mathrm{m}, 35$ aréolas em $10 \mu \mathrm{m}$.

Lâminas examinadas: 5737, 5771, 5773, 5779, 5785, 5792, 5811, 5813, 5844, 5854, 5893, 6014, 6016, 6020.

Os exemplares encontrados são muito semelhantes aos observados por Krammer \& LangeBertalot (1988), porém estes apresentam as extremidades levemente mais capitadas e menor largura (3-5 $\mu \mathrm{m})$. Nitzschia ignorata Krasske é morfologicamente similar, mas difere de $N$. clausii pelo maior comprimento valvar $(50-70 \mu \mathrm{m})$ e pela menor densidade de fíbulas em $10 \mu \mathrm{m}(8-10)$. Difere de N. scallpelliformis (Grun.) Grun. por esta apresentar o sistema de rafe inteiramente deslocado da margem e não somente no centro como em $N$. clausii. Registrada na América do Sul no rio Limahue, Chile e rio Gala, Equador (Rumrich et al. 2000). No Rio Grande do Sul, foi encontrada no lago Guaíba, no arroio Sampaio e listada para o litoral sul (Torgan et al. 1999).

7. Nitzschia dissipata var. borneensis Hust. in Schmidt's Atlas, pl. 335, figs 22-24. $1921 . \quad$ Fig. 3 a-b Valvas lineares, extremidades atenuadosubcapitadas, fíbulas não equidistantes localizadas subcentralmente, estrias inconspícuas em MO. Medidas: 57-63 $\mu \mathrm{m}$ de comprimento, $7 \mu \mathrm{m}$ de largura, 7-10 fíbulas em $10 \mu \mathrm{m}$.

Lâminas examinadas: 5997, 6014.

As características métricas e morfológicas dos exemplares encontrados conferem com o material tipo (Simonsen 1987, pl. 77, figs 8-16). Primeira citação para o Rio Grande do Sul.

\section{Nitzschia dissipata (Kütz.) Grun. var.?}

Fig. 3 c-d

Valvas levemente lanceoladas, extremidades fortemente atenuado-subcapitadas, fíbulas não equidistantes localizadas subcentralmente, estrias inconspícuas em MO. Medidas: 57-69 $\mu \mathrm{m}$ de comprimento, $6 \mu \mathrm{m}$ de largura, 7-8 fíbulas em $10 \mu \mathrm{m}$. Lâminas examinadas: 5773, 5851, 5852, 5854, 5863, 5867, 5980, 5997, 6004, 6016.

Os organismos observados diferem das variedades existentes de Nitzschia dissipata apresentadas por Mayer (1913) pelo formato lanceolado das valvas e extremidades mais fortemente atenuadas.

9. Nitzschia cf. epiphytica O. Müller, Bot. Jahrb. 36: p. 176, pl. II, figs 16, 17. $1909 . \quad$ Fig. 3 e

Valvas elípticas, extremidades cuneadas, fíbulas equidistantes, estrias inconspícuas em MO. Medidas: $6 \mu \mathrm{m}$ de comprimento, $2 \mu \mathrm{m}$ de largura, 7 fíbulas em $5 \mu \mathrm{m}$.

Lâmina examinada: 5999.

O indivíduo observado possui morfologia e medidas similares à encontrada por Hustedt (1949), porém como não foi possível confirmar o espaçamento central entre as fíbulas, assim, mantevese a identificação da espécie em conferatum. 


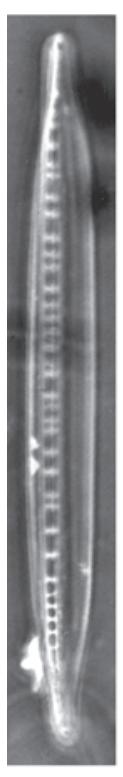

a

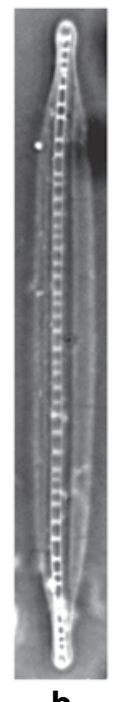

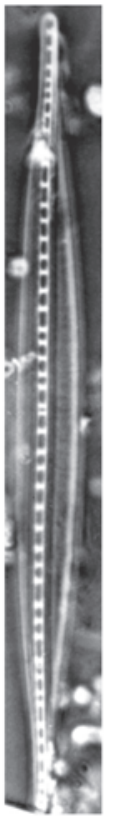

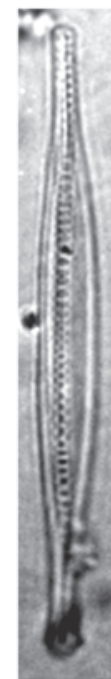

d

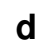

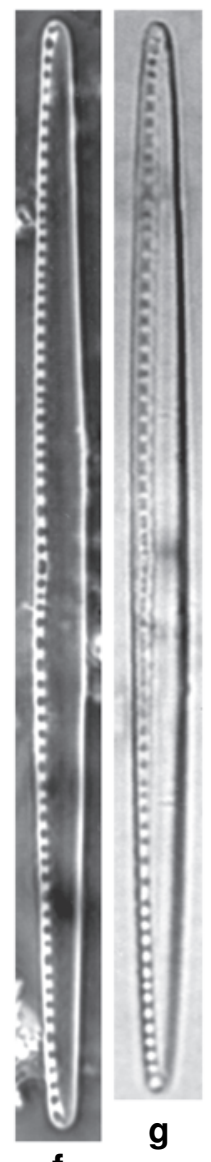

f
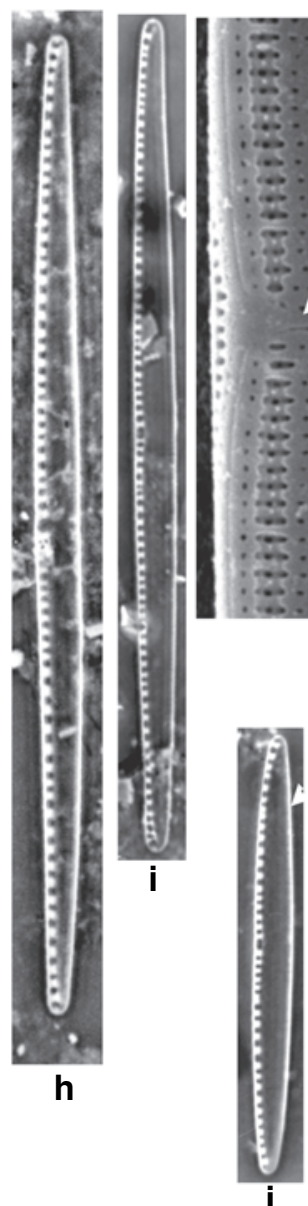

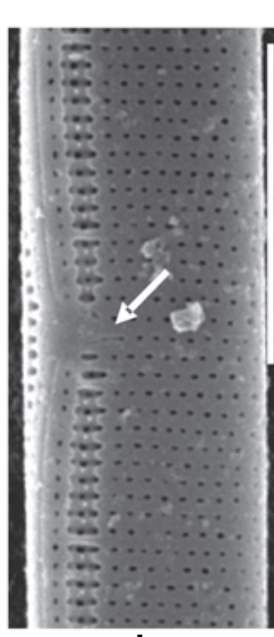

$\mathbf{k}$

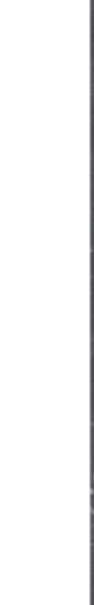

l-m

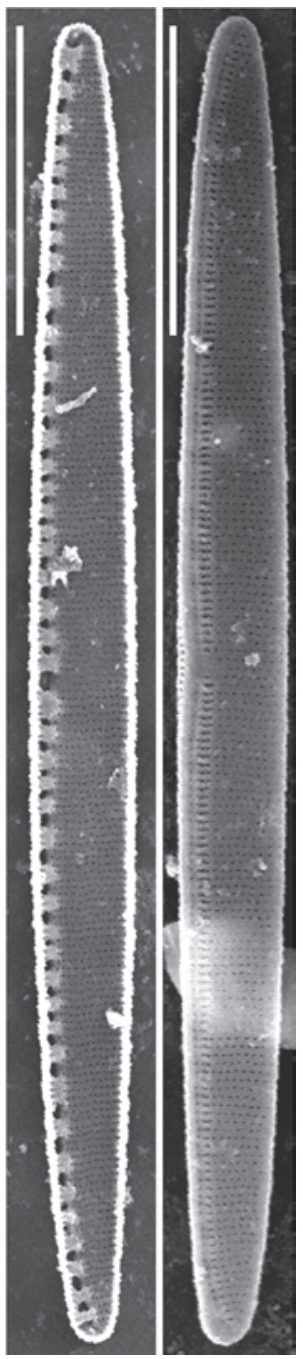

Figura 3 - MO e MEV - a, b. N. dissipata var. borneensis. c-d. $N$. dissipata var.? e. $N$. cf. epiphytica. f-m. $N$. filiformis var. filiformis, MEV - k. detalhe da área central da valva, vista externa; 1. vista interna; $\mathrm{m}$. vista externa. Escalas $=10 \mu \mathrm{m} ; \mathrm{k}=3 \mu \mathrm{m}$.

Figure 3 - LM and SEM - a, b. N. dissipata var. borneensis. c-d. $N$. dissipata var.? e. $N$. cf. epiphytica. f-m. $N$. filiformis var. filiformis, SEM - k. detail of the central area of the valve, external view; 1. internal view; $\mathrm{m}$. external view. Scale bars $=10 \mu \mathrm{m}, \mathrm{k}=3 \mu \mathrm{m}$.

10. Nitzschia filiformis var. filiformis (W. Smith) Van Heurck in Van Heurck, Syn. Diat. Bel., p. 406, fig. 33: 882, 1896.

Fig. $3 \mathrm{f}-\mathrm{m}$

Valvas lineares, extremidades arredondadas, fíbulas não equidistantes, mais espaçadas e afastadas da margem na região central, estrias inconspícuas em MO. Em MEV apresenta estrias formadas por uma fileira de aréolas, interrompidas na região central. Rafe com extremidades proximais curvadas para a região mediana das valvas. Fíbulas de tamanhos desiguais, levemente maiores na região central e em uma das extremidades valvares (Fig. 31 -m). Perpendicular a rafe, apresentam uma fileira de aréolas alongadas formada pela fusão de duas ou três aréolas. Possuem uma fileira de aréolas no manto (Fig. 3 k). Medidas: 41-95 $\mu \mathrm{m}$ de comprimento, 4-5 $\mu \mathrm{m}$ de largura, 8-11 fíbulas em 10 $\mu \mathrm{m}, 32-34$ estrias em $10 \mu \mathrm{m}$.

Lâminas examinadas: 5737, 5771, 5779, 5785, 5809, 5811, 5983, 5984, 5986, 5994, 5997, 5999, 6004, 6014, 6016, 6018, 6020, 6023 .

Os indivíduos observados concordam métrica e morfologicamente com os demonstrados na flora 
da Europa (Krammer \& Lange-Bertalot 1988; Hustedt 1930). Este táxon foi encontrado também no Chile (Rumrich et al. 2000) e no rio Amazonas, Brasil (Metzeltin \& Lange-Bertalot 1998). No Rio Grande do Sul, foi observada no lago Guaiba e em áreas úmidas no litoral sul (Torgan et al. 1999).

11. Nitzschia filiformis var. conferta (Richter) Lange-Bert., Bibl. Diatomol. 15: 18. 1987.

Fig. 4 a-h

Valvas levemente sigmóides, extremidades atenuadas, subcapitadas, fíbulas não equidistantes interrompidas por maior espaçamento na região central, estrias inconspícuas em MO. Em MEV apresenta estrutura interna e externa semelhante a var. filiformis (Fig. $3 \mathrm{f}-\mathrm{h}$ ). Medidas: 28-57 $\mu \mathrm{m}$ de comprimento, 4-5 $\mu \mathrm{m}$ de largura, 8-9 fíbulas em $10 \mu \mathrm{m}, 31-34$ estrias em $10 \mu \mathrm{m}, 35-36$ aréolas em $10 \mu \mathrm{m}$.

Lâminas examinadas: 5737, 5809, 5983, 6004.

Os indivíduos encontrados são morfologicamente semelhantes aos ilustrados por Krammer \& Lange-Bertalot (1988). Esta variedade difere da var. filiformis por apresentar menor tamanho e formato das extremidades valvares. Assemelha-se a Nitzschia subcohaerens (Grun.) Van Heurck var. scotica Grun., entretanto, esta se apresenta mais nitidamente afilada e sigmóide em relação a $N$. filiformis var. conferta. Na América do Sul, a variedade também foi encontrada no rio Cebolla, Uruguai (Metzeltin et al. 2005). No Rio Grande do Sul, é citada para o rio Pardinho (Lobo et al. 2004b).

12. Nitzschia cf. frequens Hust., Abehr. Natur. Ver. Bremen 34: 348, figs 52-54. $1957 . \quad$ Fig. 4 i-1

Valvas linear-lanceoladas, levemente côncavas na margem fibulada, extremidades cuneadas, capitadorostradas, fíbulas equidistantes interrompidas por maior espaçamento na região central. Medidas: 71-76 $\mu \mathrm{m}$ de comprimento, 4-6 $\mu \mathrm{m}$ de largura, 11-12 fíbulas em $10 \mu \mathrm{m}, 29-30$ estrias em $10 \mu \mathrm{m}$.

Lâminas examinadas: 5737, 5771, 5779, 5785, 5999.

Os exemplares observados são morfologicamente semelhantes ao ilustrado por Metzeltin et al. (2005, pl. 218, fig. 5) para o arroio Aiguá, Uruguai e identificado como Nitzschia frequens. Manteve-se a identificação do material em conferatum, pois o material tipo apresentado por Hustedt (1957) possui menor comprimento (45-65 $\mu \mathrm{m})$ e menor número de estrias (cerca de 24 em $10 \mu \mathrm{m})$.
13. Nitzschia gracilis Hantzsch in Rabenhorst, Alg. Sachs. Dec. 95/96: 946. 1860. Fig. $4 \mathrm{~m}-\mathrm{q}$

Valvas linear-lanceoladas, extremidades afiladas arredondadas, fíbulas equidistantes, estrias inconspícuas em MO. Medidas: 51-89 $\mu \mathrm{m}$ de comprimento; 3-5 $\mu \mathrm{m}$ de largura; 11-14 fíbulas em $10 \mu \mathrm{m}$.

Lâminas examinadas: 5737, 5738, 5772, 5773, 5774, 5779, 5782, 5786, 5789, 5792, 5809, 5811, 5813, 5844, 5848, 5849, 5851, 5854, 5859, 5863, 5874, 5880, 5893, 5894, 5980, 5994, 5997, 5999, 6008, 6014, 6016, 6022, 6023.

Os exemplares observados concordam métrica e morfologicamente com Hustedt (1930), Lange-Bertalot \& Simonsen (1978)e Krammer \& Lange-Bertalot(1988). Difere de N. paleaceae Grun. na distribuição das fíbulas: em $N$. gracilis são equidistantes, enquanto que em $N$. paleaceae são interrompidas por maior espaçamento na região central da valva (Krammer \& Lange-Bertalot 1988). No Rio Grande do Sul, foi anteriormente encontrada no lago Guaíba, na represa Águas Belas, em Viamão, em ambientes lênticos e lóticos do Parque Estadual do Turvo (Torgan et al., 1999), no rio Pardinho (Lobo et al. 2004b). Foi listada para as áreas úmidas do litoral sul (Torgan et al. 1999) e para a lagoa Itapeva (Cardoso \& Motta-Marques 2003, 2004).

14. Nitzschia intermedia Hantzsch ex Cleve \& Grunow, K. Svenska Vet-Akad. Handl., ser. 4, 17 (2): 95.1880.

Fig. 4 r-y, 5 i-d

Valvas lineares a linear-lanceoladas, extremidades levemente cuneadas, fíbulas equidistantes, estrias inconspícuas em MO. Medidas: 26-161 $\mu \mathrm{m}$ de comprimento, 4-6 $\mu \mathrm{m}$ de largura, 8-12 fíbulas em $10 \mu \mathrm{m}$.

Lâminas examinadas: 5737, 5771, 5773, 5774, 5775, 5779, 5783, 5786, 5789, 5792, 5808, 5809, 5811, 5813, 5834A, 5854, 5859, 5874, 5980, 5983, 5892, 5893, 5894, 5973, 5975, 5999, 6004, 6008, 6014, 6015, 6016, 6018, 6022.

Os indivíduos apresentaram grande plasticidade morfológica nas amostras analisadas. Alguns se assemelham a N. fruticosa Hust. (Fig. 4 $\mathrm{r}-\mathrm{t})$, mas diferem desta por apresentar menores dimensões (20-83 $\mu \mathrm{m}$ de comprimento e 2,5-4,5 $\mu \mathrm{m}$ de largura) e maior densidade de fíbulas (13-18 em $10 \mu \mathrm{m})$ e estrias (29-36 em $10 \mu \mathrm{m})$, segundo Krammer \& Lange-Bertalot (1988). No Rio Grande do Sul, foi listada para o litoral sul (Torgan et al. 1999).

15. Nitzschia latens Hust., Explor. Parc. Natl. Albert, Mission, H. Damas 8, p. 148, pl. 13: 30, 31. 1949.

Fig. 5 e

Valvas lineares, extremidades cuneadas, fíbulas não equidistantes, estrias inconspícuas em MO. Medidas: $20 \mu \mathrm{m}$ de comprimento, $4 \mu \mathrm{m}$ de largura, 18 fíbulas em $10 \mu \mathrm{m}$. 


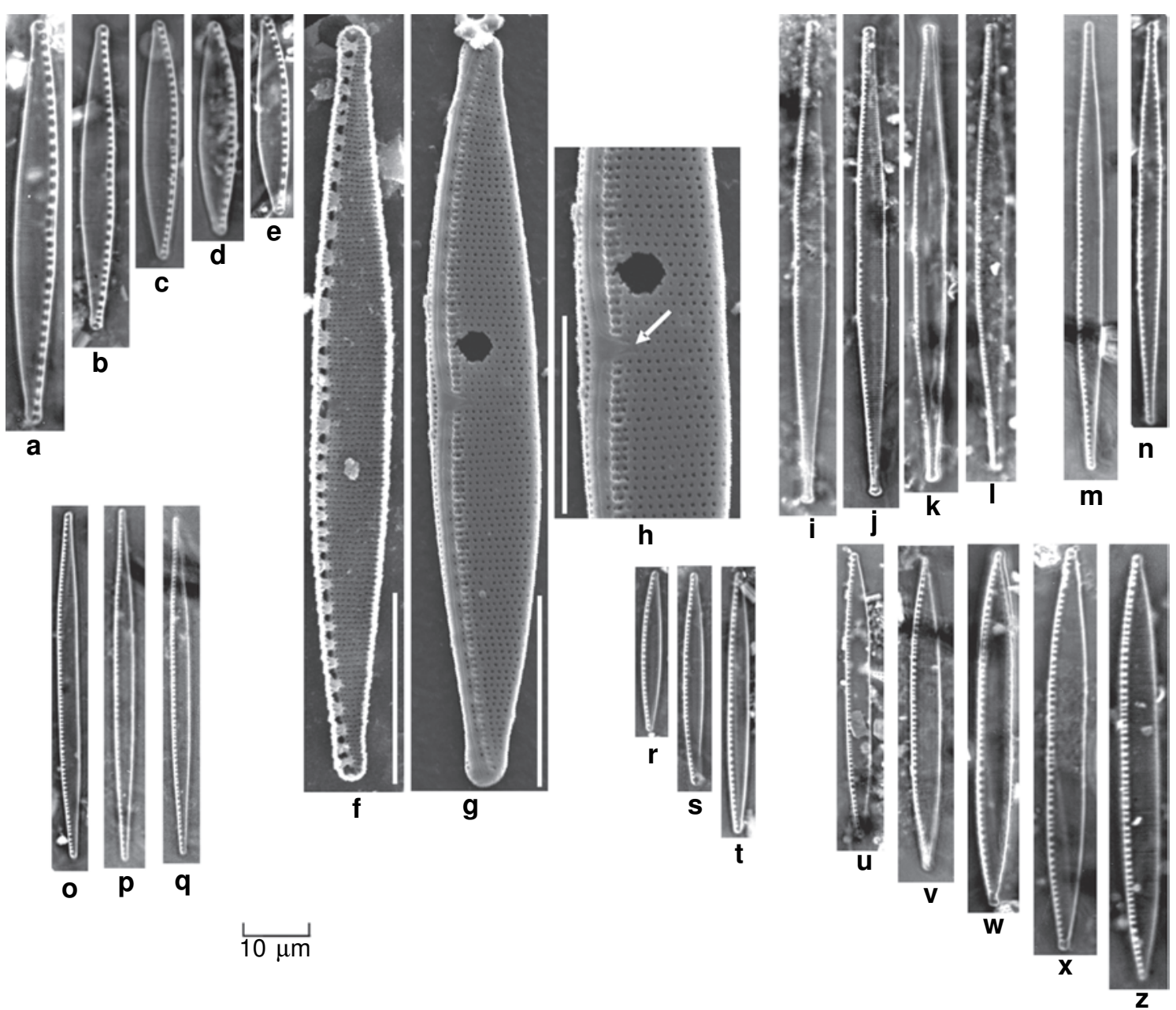

Figura 4 - MO e MEV - a-h. N. filiformis var. conferta, MEV - f. vista interna; g. vista externa; h. detalhe da região central da valva, vista externa. i-l. $N$. cf. frequens. m-q. $N$. gracilis. r-y. $N$. intermedia. Escalas $=10 \mu \mathrm{m} ; \mathrm{h}=3 \mu \mathrm{m}$. Figure 4 - LM and SEM - a-h. N. filiformis var. conferta, SEM - f. internal view; g. external view; h. detail of the central area of the valve, external view. i-1. $N$. cf. frequens. m-q. $N$. gracilis. r-y. $N$. intermedia. Scale bars $=10 \mu \mathrm{m}, \mathrm{h}=3 \mu \mathrm{m}$.

Lâmina examinada: 5771 .

O indivíduo encontrado concorda métrica e morfologicamente com o material tipo apresentado por Hustedt (1949). Esta espécie é pouco conhecida sendo registrada somente para o centro da África.

16. Nitzschia linearis (Agardh) W. Smith var. linearis, Syn. Brit. Diat. 1: 39, pl. 13: 110, pl. 31: 110. 1853.

Fig. 5 f-h

Valvas lineares longas, levemente côncava na margem fibulada, extremidades subcapitadas, fíbulas alongadas trasapicalmente e equidistantes, interrompidas por maior espaçamento na região central, estrias densas. Medidas: $82-160 \mu \mathrm{m}$ de comprimento, 5-8 $\mu \mathrm{m}$ de largura, 7-9 fíbulas em $10 \mathrm{~mm}, 31-32$ estrias em $10 \mu \mathrm{m}$.

Lâminas examinadas: $5737,5771,5772,5774,5775$, 5777, 5785, 5809, 5811, 5813, 5842, 5844, 5848, 5851, 5854, 5874, 5880, 5892, 5975, 5980, 5997, 6016, 6018, $6020,6023$.

Os organismos concordam métrica e morfologicamente com o material apresentado por Krammer \& Lange-Bertalot (1988). No Rio Grande do Sul, foi encontrada no arroio Boa Vista, em sistemas lóticos do rio Jacuí, no arroio Sampaio e no litoral sul (Torgan et al. 1999, Lobo et al. 2004a,b, Oliveira et al.2001). Foi listada para a lagoa Itapeva (Cardoso \& Motta-Marques 2003, 2004). 

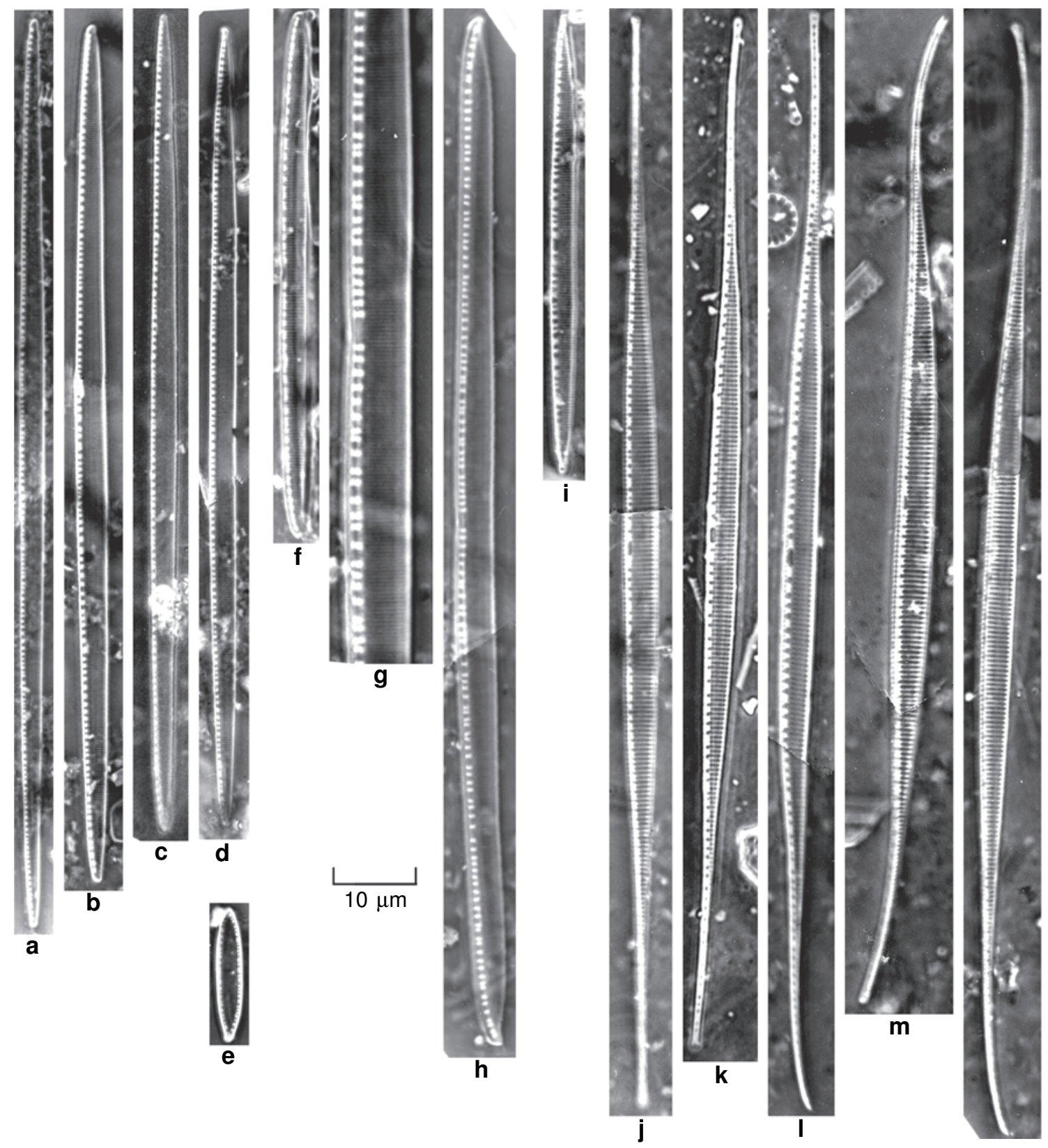

n

Figura 5-MO - a-d. N. intermedia. e. N. latens. f-h. N. linearis var. linearis. i. N. linearis var. tenuis. k-n. N. lorenziana. Escala $=10 \mu \mathrm{m}$.

Figure 5 - LM - a-d. $N$. intermedia. e. $N$. latens. f-h. N. linearis var. linearis. i. $N$. linearis var. tenuis. k-n. $N$. lorenziana. Scale bar $=10 \mu \mathrm{m}$.

17. Nitzschia linearis var. tenuis (W. Smith) Grun in Cleve \& Grunow, K. Svenska Vet-Akad. Handl., ser. 4, 17 (2): 91. 1880.

Fig. 5 i

Valvas lineares, extremidades subcapitadas, fíbulas equidistantes interrompidas por maior espaçamento na região central. Medidas: $72 \mu \mathrm{m}$ de comprimento, $4 \mu \mathrm{m}$ de largura, 9 fíbulas em $10 \mu \mathrm{m}$, 23 estrias em $10 \mu \mathrm{m}$.

Lâmina examinada: 5980.

O espécime encontrado assemelha-se morfologicamente ao citado para Europa (Krammer \& Lange-Bertalot 1988). Esta variedade difere da 
var. linearis por apresentar menor densidade de estrias e maior relação comprimento/largura. Primeira citação para o Rio Grande do Sul.

18. Nitzschia lorenziana Grun. in Cleve \& Grunow, K. Svenska Vet-Akad. Handl., ser. 4, 17(2): 101. 1880.

Fig. 5 k-n

Valvas linear-lanceoladas a sigmóides, extremidades atenuado-apiculadas, fíbulas equidistantes, interrompidas por maior espaçamento na região central. Medidas: 142-191 $\mu \mathrm{m}$ de comprimento, 4-5 $\mu \mathrm{m}$ de largura, 6-10 fíbulas em 10 $\mu \mathrm{m}, 13-18$ estrias em $10 \mu \mathrm{m}$.

Lâminas examinadas: 5737, 5779, 5785, 5792, 6014.

Este táxon assemelha-se morfologicamente a $N$. andicola Lange-Bert. \& Rumrich (Rumrich et al. 2000), entretanto, esta última possui menores dimensões (70$90 \mu \mathrm{m}$ de comprimento e 3-3,6 $\mu \mathrm{m}$ de largura). No Rio Grande do Sul, esta espécie foi encontrada nas lagoas, rios e banhados da região do litoral (Torgan et al. 1999).

19. Nitzschia microcephala Grun. in Cleve \& Grunow, K. Svenska Vet-Akad. Handl., ser. 4, 17(2): 96. 1880. Fig. 6 a-g

Valvas lineares, extremidades capitadas a subcapitadas, fíbulas não equidistantes interrompidas por espaçamento na região central, estrias inconspícuas em MO. Em MEV pode-se observar uma fileira de aréolas formando cada estria e que as fíbulas são de mesmo tamanho (Fig. 6 a). Medidas: 9-15 $\mu \mathrm{m}$ de comprimento, 3-4 $\mu \mathrm{m}$ de largura, 13-16 fíbulas em $10 \mu \mathrm{m}, 35$ estrias em $10 \mu \mathrm{m}$.

Lâminas examinadas: 5983, 5999.

Os organismos observados conferem com os apresentados para a Europa (Hustedt 1930, Krammer \& Lange-Bertalot 1988). Na América do Sul, esta espécie foi encontrada em Small Creck, Uruguai (Metzeltin et al. 2005). No Rio Grande do Sul, foi listada nas áreas úmidas no litoral sul (Torgan et al. 1999).

20. Nitzschia nana Grun. in Van Heurck, Syn. Diat. Bel., pl. 67:3.1881.

Fig. 6 h-p

Valvas levemente sigmóides, extremidades atenuada subrostradas, fíbulas equidistantes, interrompidas por maior espaçamento na região central e afastadas da margem, estrias inconspícuas em MO. Em MEV apresenta estrias formadas por uma fileira de aréolas. Fíbulas de tamanhos desiguais, levemente maiores na região mediana (Fig. 6n). Perpendicular a rafe, observa-se também, uma fileira de aréolas alongadas e uma fileira de aréolas no manto (Fig. 6o-p). Medidas: 39-75 $\mu \mathrm{m}$ de comprimento, 4-5 $\mu \mathrm{m}$ de largura, 8-10 fíbulas em $10 \mu \mathrm{m}, 33-34$ estrias em $10 \mu \mathrm{m}$.

Lâminas examinadas: $5737,5771,5772,5773,5779,5780$, $5809,5811,5846,5848,5849,5851,5854,5859,5785,5893$, 5894, 5973, 5980, 5997, 6004, 6018, 6022, 6023.

Os exemplares observados conferem com as medidas e morfologia apresentada por Krammer \& Lange-Bertalot (1988) para a flora da Europa. Difere de Nitzschia scallpeliformis (Grun.) Grun. por esta apresentar o sistema de rafe inteiramente deslocado da margem e não somente na região central, como na espécie em questão. Na América do Sul, foi encontrada no arroio del Leon no Uruguai (Metzeltin et al. 2005). No Rio Grande do Sul, foi encontrada na laguna dos Patos e arroios do baixo Jacuí (Torgan etal. 1999).

21. Nitzschia palea (Kütz.) W. Smith, Syn. Brit. Diat., vol. 2, p. 89.1856. Fig. 6 q-u

Valvas lineares, extremidades cuneadosubcapitadas, fíbulas equidistantes interrompidas por maior espaçamento na região central, estrias inconspícuas em MO. Medidas: 20-46 $\mu \mathrm{m}$ de comprimento, 4-5 $\mu \mathrm{m}$ de largura, 10-14 fíbulas em $10 \mu \mathrm{m}$.

Lâminas examinadas: 5737, 5771, 5772, 5773, 5774 , 5775, 5779, 5782, 5783, 5785, 5786, 5789, 5792, 5808, 5809, 5811, 5813, 5834A, 5844, 5846, 5849, 5853, 5854, 5859, 5867, 5869, 5874, 5880, 5892, 5893, 5894, 5973, 5975, 5980, 5983, 5999, 6004, 6008, 6010, 6014, 6015, 6016, 6018, 6020, 6022, 6023.

O material encontrado concorda com as características métricas e morfológicas apresentadas por Krammer \& Lange-Bertalot (1988) para a Europa. No Rio Grande do Sul, esta espécie esta bem distribuída em todo o estado (Torgan et al. 1999; Raupp et al. 2006).

22. Nitzschia palea var. debilis (Kütz.) Grun. in Cleve \& Grunow, K. Svenska Vet-Akad. Handl., ser. 4, 17 (2): 96. 1880.

Fig. $6 \mathrm{v}-\mathrm{Z}$

Valvas lineares a linear-lanceoladas, extremidades levemente cuneadas, fíbulas equidistantes interrompidas por maior espaçamento na região central, estrias inconspícuas em MO. Medidas: $18-48 \mu \mathrm{m}$ de comprimento, 3-4 $\mu \mathrm{m}$ de largura, 12-15 fíbulas em $10 \mu \mathrm{m}$.

Lâminas examinadas: 5737, 5766, 5771, 5773, 5774, 5775, 5780, 5785, 5786, 5792, 6008 .

O material encontrado confere com as características métricas e morfológicas apresentadas por Krammer \& Lange-Bertalot (1988). Na América do Sul, esta variedade é citada por Rumrich et al. (2000) para a flora do Chile. No Rio Grande do Sul, foi 

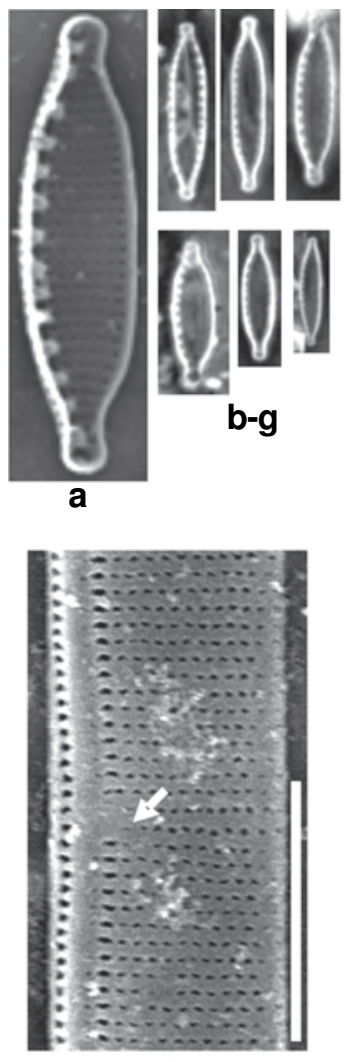

p

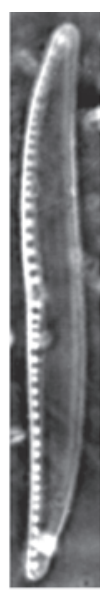

h


u
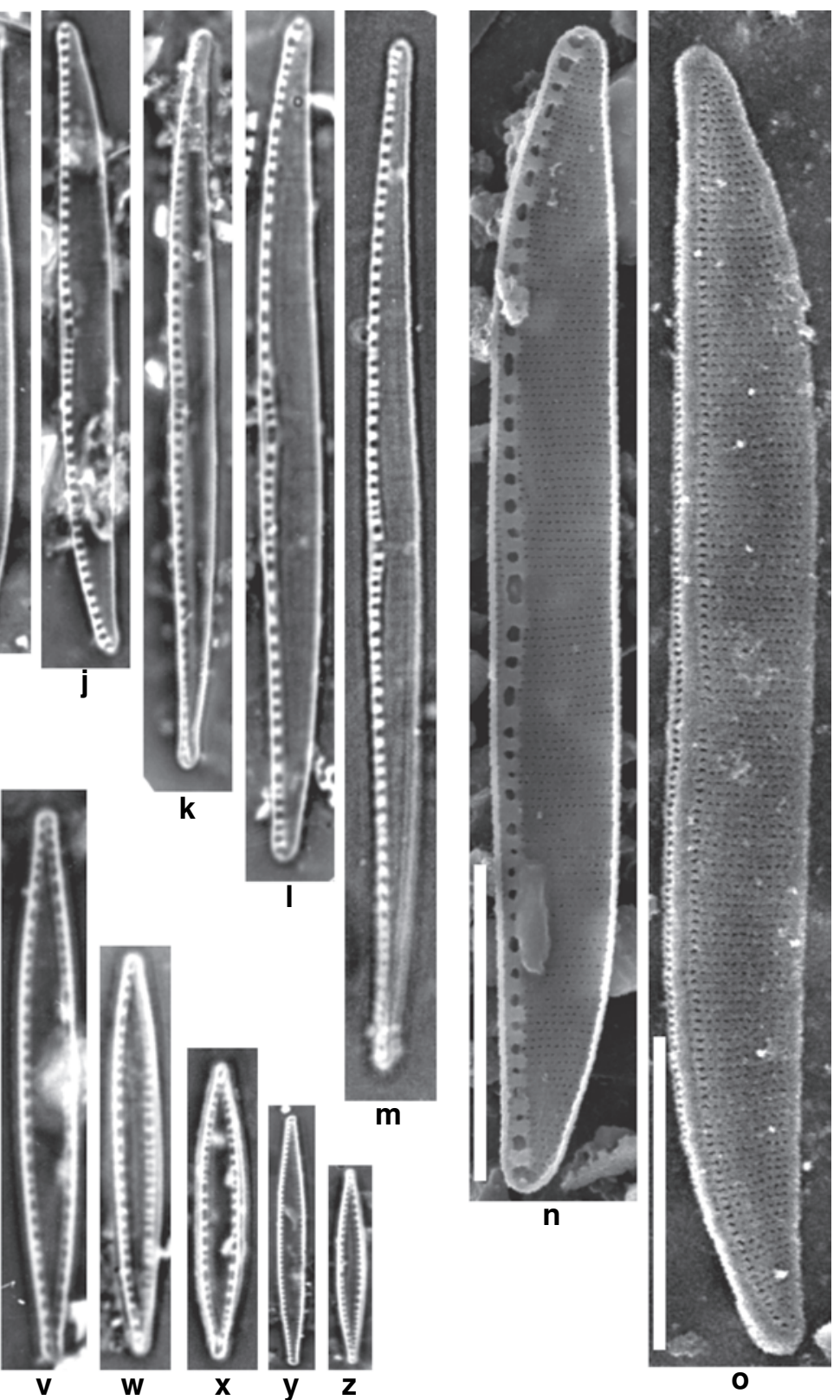

Figura 6-MO e MEV - a-g. N. microcephala, MEV - a. vista interna. h-p. N. nana, MEV - n. vista interna; o. vista externa; p. detalhe da área central, vista externa. q-u. $N$. palea var. palea. v-z. $N$. palea var. debilis. Escalas $=10 \mu \mathrm{m} ; \mathrm{p}=5 \mu \mathrm{m}$. Figure 6 - LM and SEM - a-g. N. microcephala, SEM - a. internal view. h-p. N. nana, SEM - n. internal view; o. external view; p. detail of the valve's central area, external view. q-u. $N$. palea var. palea. v-z. $N$. palea var. debilis. Scale bars $=10 \mu \mathrm{m}, \mathrm{p}=5 \mu \mathrm{m}$.

encontrada na represa Águas Belas, em Viamão, na planície costeira e no lago Guaiba (Torgan et al. 1999).

23. Nitzschia pseudofonticola Hust., Abh. Naturw. Ver. Bremen 32: 209, figs 4, 5. $1942 . \quad$ Fig. 7 a-f

Valvas linear-lanceoladas, extremidades atenuadas, subcapitado-rostradas, fíbulas equidistantes, estrias inconspícuas em MO. Em MEV observam-se estrias formadasporumafileira de aréolase fibulas de igual tamanho (Fig. 7a). Medidas: 25-41 $\mu$ mdecomprimento,4-5 $\mu$ mde largura, 7-9 fíbulas em $10 \mu \mathrm{m}, 36-41$ estrias em $10 \mu \mathrm{m}$. Lâminas examinadas: 5737, 5738, 5771, 5779, 5783, 5785, 5808, 5813, 5844, 5849, 5859, 5973, 5893, 5983, 5984, 5994, 5997, 6004. 6014, 6016, 6018. 


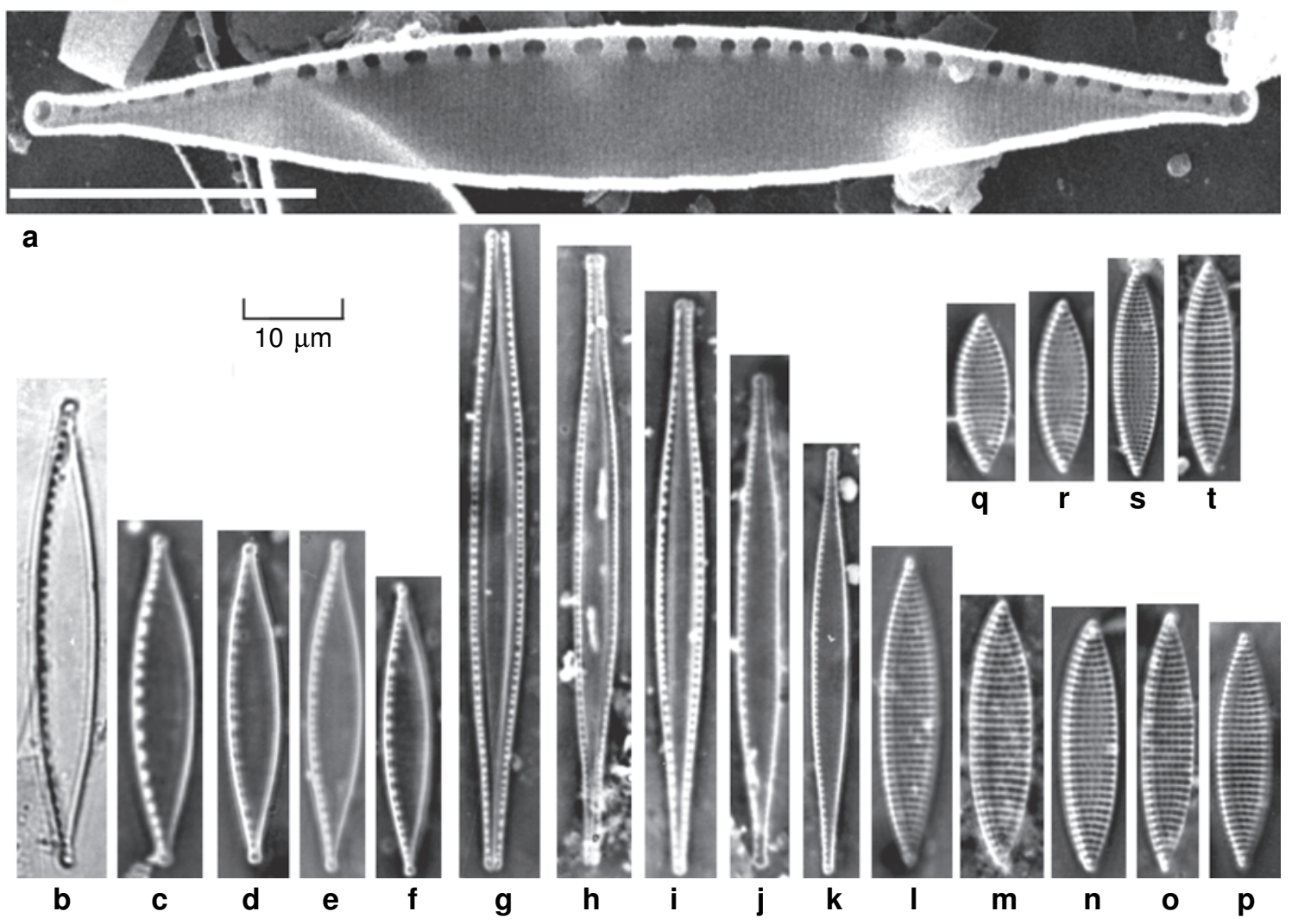

Figura 7-MO e MEV - a-f. N.pseudofonticola, MEV - a. vista interna. g-k. N. pumila. 1-t. N. rautebachiae. Escala $=10 \mu \mathrm{m}$. Figura 7 - LM and SEM - a-f. N. pseudofonticola, MEV - a. internal view. g-k. N. pumila. 1-t. N. rautebachiae. Scale bar $=10 \mu \mathrm{m}$.

Os indivíduos observados concordam com os apresentados para a Europa (Krammer \& LangeBertalot 1988; Simonsen 1987).

24. Nitzschia pumila Hust., Archiv. Hydrobiol. 48: 480, figs 67-69. 1954.

Fig. 7 g-k

Valvas linear-lanceoladas, extremidades atenuado-subrostradas, fíbulas equidistantes, estrias inconspícuas em MO. Medidas: 36-60 $\mu \mathrm{m}$ de comprimento, 4-6 $\mu \mathrm{m}$ de largura, 12-15 fíbulas em $10 \mu \mathrm{m}$. Primeira citação para o Rio Grande do Sul.

Lâminas examinadas: 5737, 5738, 5764, 5774, 5775, $5777,5846,5848,5849,5851,5854,5863,5867,5869$, 5980, 5983, 5999, 6014, 6016, 6018, 6022.

Os indivíduos encontrados demonstraram maior amplitude métrica em relação ao observado por Krammer \& Lange-Bertalot (1988) para a flora da Europa (30-37 $\mu \mathrm{m}$ de comprimento, 2,5-3 $\mu \mathrm{m}$ de largura, 14-18 fíbulas em $10 \mu \mathrm{m})$.
25. Nitzschia rautenbachiae Choln., Öesterr. Bot. Z. 104: 76, figs 228-232. 1957.

Fig. $71-\mathrm{t}$

Valvas linear-lanceoladas, extremidades cuneado-apiculadas, fíbulas equidistantes, estrias nitidamente pontuadas. Medidas: 16-27 $\mu \mathrm{m}$ de comprimento, 5-6 $\mu \mathrm{m}$ de largura, 14-17 fíbulas em $10 \mu \mathrm{m}, 14-17$ estrias em $10 \mu \mathrm{m}, 12-14$ aréolas em $10 \mu \mathrm{m}$.

Lâminas examinadas: 5779, 5807, 5893, 5997, 5999, 6004.

O material observado enquadra-se na descrição e medidas do material encontrado no sul da África (Schoeman \& Archibald 1966). Assemelha-se a Nitzschia rochensis Metz. et al., porém esta apresenta diferentes dimensões (16-39 $\mu \mathrm{m}$ de comprimento e 3,3-3,7 $\mu \mathrm{m}$ de largura) e maior densidade de aréolas (15-18 em $10 \mu \mathrm{m})$ em comparação a $N$. rautenbachiae. Outra espécie próxima é $N$. silicula Hust., entretanto, esta possui menor largura $(4,3-4,5 \mu \mathrm{m})$ e número de aréolas em $10 \mu \mathrm{m}$ (7-8). Este táxon foi encontrado também no Uruguai (Metzeltin et al. 2005). 

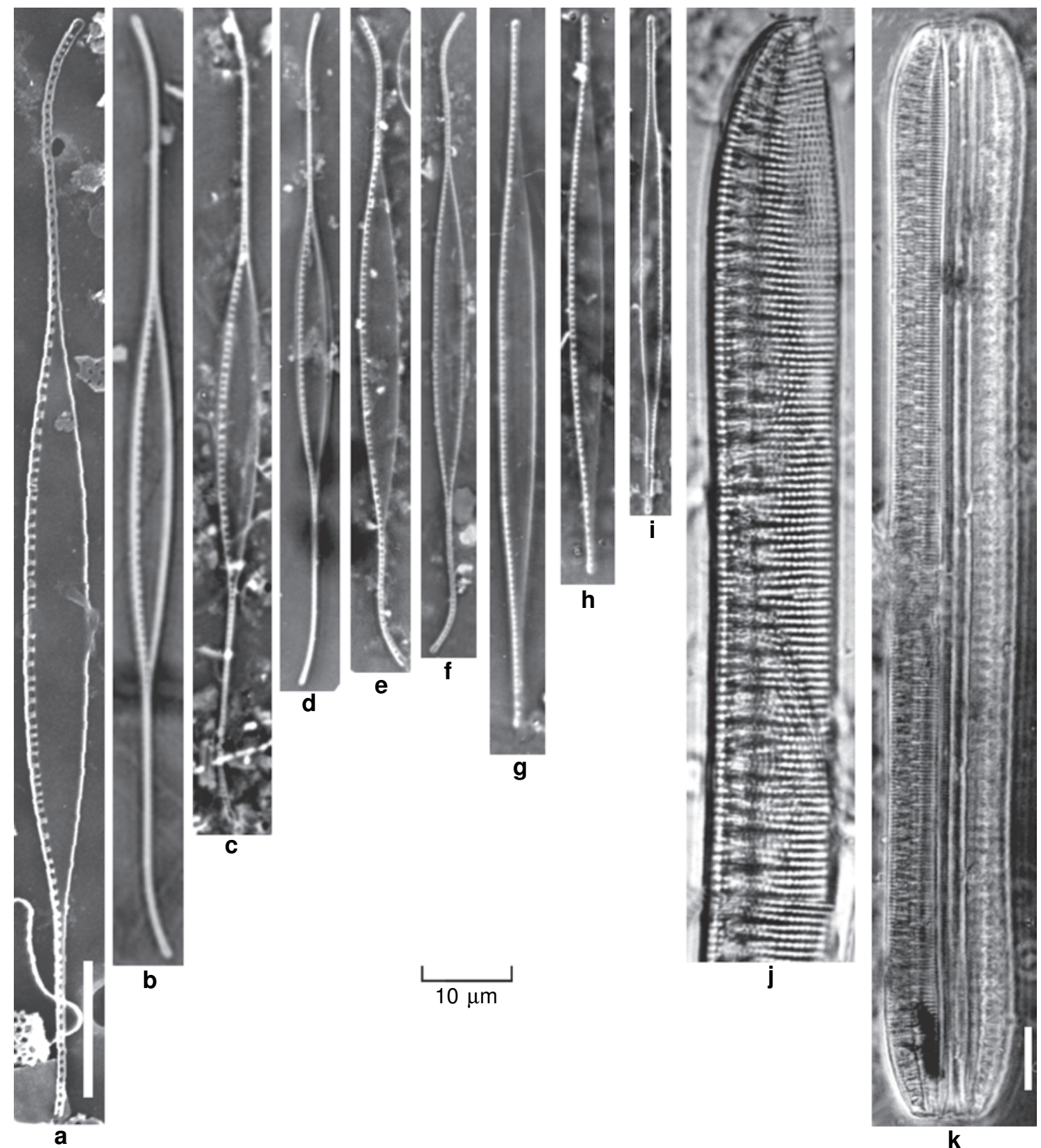

a

Figura 8 - MO e MEV - a-f. $N$. reversa, MEV - a. vista interna. g-i. $N$. rostellata. $\mathrm{j}-\mathrm{k}$. $N$. scalaris. Escala $=10 \mu \mathrm{m}$. Figura 8 - LM and SEM - a-f. N. reversa, SEM - a. internal view. g-i. N. rostellata. j-k. N. scalaris. Scale bar $=10 \mu \mathrm{m}$.

26. Nitzschia reversa W. Smith, Syn. Brit. Diat. 1: 43, pl. 15: fig. 121. 1853.

Fig. 8 a-f

Valvas lanceoladas, extremidades fortemente atenuado-arrendondadas curvadas para sentidos opostos, fíbulas não equidistantes, interrompidas por maior espaçamento na região central, estrias inconspícuas em MO. Medidas: $68-104 \mu \mathrm{m}$ de comprimento, $4-5 \mu \mathrm{m}$ de largura, $9-15$ fíbulas em $10 \mu \mathrm{m}$.
Lâminas examinadas: 5737, 5738, 5771, 5773, 5779, 5785, 5792, 5808, 5809, 5851, 5852, 5853, 5973, 5980, 5994, 6014, 6018.

As medidas e formas dos indivíduos ilustrados em Krammer \& Lange-Bertalot (1988) e Van Heurck (1885) conferem com o material encontrado. No Rio Grande do Sul, esta espécie é citada para lagoas do litoral sul (Torgan et al. 1999). 
27. Nitzschia rostellata Hust. in Schmidt's Atlas, pl.348: 9.1922

Fig. 8 g-i

Valvas linear-lanceoladas, extremidades atenuado-arredondadas, fíbulas equidistantes, estrias inconspícuas em MO. Medidas: $67-81 \mu \mathrm{m}$ de comprimento; 4-5 $\mu \mathrm{m}$ de largura; 10-14 fíbulas em $10 \mu \mathrm{m}$.

Lâminas examinadas: 5737, 5771, 5980, 6018, 6016.

Os exemplares encontrados na França, Espanha, Venezuela (Lange-Bertalot \& Simonsen 1978) e Bélgica (Germain 1981) diferem do observado por apresentarem estrias conspícuas. $N$. rostellata difere de $N$. elegans Hust. por esta apresentar menor largura $(2,5 \mu \mathrm{m})$, maior densidade de fíbulas (13-16 em $10 \mu \mathrm{m})$ e pela presença de espaçamento central entre as fíbulas. Na América do Sul, foi encontrada no Uruguai (Metzeltin et al. 2005). No Rio Grande do Sul, foi observada em ambientes lênticos e lóticos do Parque Estadual do Turvo (Torgan et al. 1999).

28. Nitzschia scalaris (Her.) W. Smith, Syn. Brit. Diat. 1: 39. 1853.

Fig. 8 j-k

Valvas lineares, extremidades cuneadoarrendondadas, fíbulas marginais grosseiras e alongadas para o centro da valva e não equidistantes, estrias nitidamente pontuadas. Medidas: $131-293 \mu \mathrm{m}$ de comprimento; $12-18 \mu \mathrm{m}$ de largura; $3-4$ fíbulas em $10 \mu \mathrm{m} ; 9-11$ estrias em $10 \mu \mathrm{m}$.

Lâminas examinadas: 5737, 5774, 5809, 5849, 5859, 5880, 5986, 5893, 5980.

Os exemplares encontrados conferem morfologicamente com os apresentados por Krammer \& Lange-Bertalot (1988) e Hustedt (1930). Porém, foi observado um exemplar com $131 \mu \mathrm{m}$ de comprimento, sendo que ambos os autores apresentam indivíduos com medida mínima de $150 \mu \mathrm{m}$ de comprimento. No Rio Grande do Sul, foi encontrada no litoral norte (Torgan et al. 1999) e listada para a lagoa Itapeva (Cardoso \& Motta Marques 2004).

29. Nitzschia scalpelliformis (Grun.) Grun. in Cleve \& Grunow, K. Svenka. Vet.-Akad., Handl. ser. 4, 17 (2): 92.1880.

Fig. 9 a-c

Valvas lineares, extremidades atenuadosubrostradas levemente curvadas para sentidos opostos, fíbulas equidistantes deslocadas da margem, interrompidas por maior espaçamento na região central, estrias inconspícuas em MO. Medidas: 35-69 $\mu \mathrm{m}$ de comprimento, 5-6 $\mu \mathrm{m}$ de largura, 8-9 fíbulas em $10 \mu \mathrm{m}$.

Lâminas examinadas: 5737, 5771, 5792, 5809, 5813, 5844, 5859, 5983, 5980, 5984, 5994, 5999, 6004, 6014.
Os exemplares concordam métrica e morfologicamente com o material observado por Krammer \& Lange-Bertalot (1988) para a flora da Europa. Este táxon difere de $N$. nana por possuir sistema de rafe inteiramente afastado da margem valvar. Pode-se encontrar com frequiência indivíduos com a frústula inteira, mostrando as fíbulas em ambas as margens. No Rio Grande do Sul, foi registrada para o lago Guaiba, represa Águas Belas e listada para as áreas úmidas do litoral sul (Torgan et al. 1999).

30. Nitzschia sigma (Kütz.) W. Smith, Syn. Brit. Diat. 1: 39. 1853.

Fig. 9d-h

Valvas linear-lanceoladas, extremidades atenuado-subcapitadas, curvadas para sentidos opostos, fíbulas alongadas equidistantes, estrias nitidamente pontuadas. Em MEV observam-se estrias formadas por fileira simples de aréolas alongadas e fíbulas de mesmo tamanho (Fig. 9 h). Medidas: $78-155 \mu \mathrm{m}$ de comprimento, 5-13 $\mu \mathrm{m}$ de largura; 8-12 fíbulas em $10 \mu \mathrm{m}, 30-31$ estrias em $10 \mu \mathrm{m}$. Lâminas examinadas: 5737, 5738, 5771, 5774, 5775, 5779, 5785, 5792, 5808, 5842, 5845, 5846, 5880, 5973, 5983, 5986, 5997, 5999, 6004, 6016, 6018, 6020.

Os indivíduos observados assemelham-se ao material apresentado por Krammer \& Lange-Bertalot (1988) para a flora da Europa, assim como para a flora da Bélgica (Van Heurk 1885) e Inglaterra (Hartley 1996). Na América do Sul, este táxon foi encontrado no Uruguai por Metzeltin et al. (2005). No Rio Grande do Sul, foi encontrado em vários ambientes lênticos e lóticos (Torgan et al. 1999, Lobo et al. 2004b).

31. Nitzschia solita Hust., Archiv. Hydrobiol. 48: 152, figs. 3, 4. 1953.

Fig. 9 i-1

Valvas lineares a linear-lanceoladas, extremidades cuneadas a levemente rostradas, fíbulas equidistantes, estrias nitidamente pontuadas. Medidas: 22-44 $\mu \mathrm{m}$ de comprimento, 4-5 $\mu \mathrm{m}$ de largura, 10-15 fíbulas em 10 $\mu \mathrm{m}, 24-27$ estrias em $10 \mu \mathrm{m}$.

Lâminas examinadas: 5737, 5997.

Os indivíduos observados concordam com o material apresentado para Europa (Krammer \& Lange-Bertalot 1988). Esta espécie difere de $N$. amphibia, por esta possuir menor densidade de fíbulas (7-9) e estrias (15-19) em $10 \mu \mathrm{m}$. Outro táxon afim é $N$. amphibioides Hust, mas este também apresenta menor densidade de fíbulas (5-7) e estrias (11,5-14) em $10 \mu \mathrm{m}$. Primeira citação para o Rio Grande do Sul. 

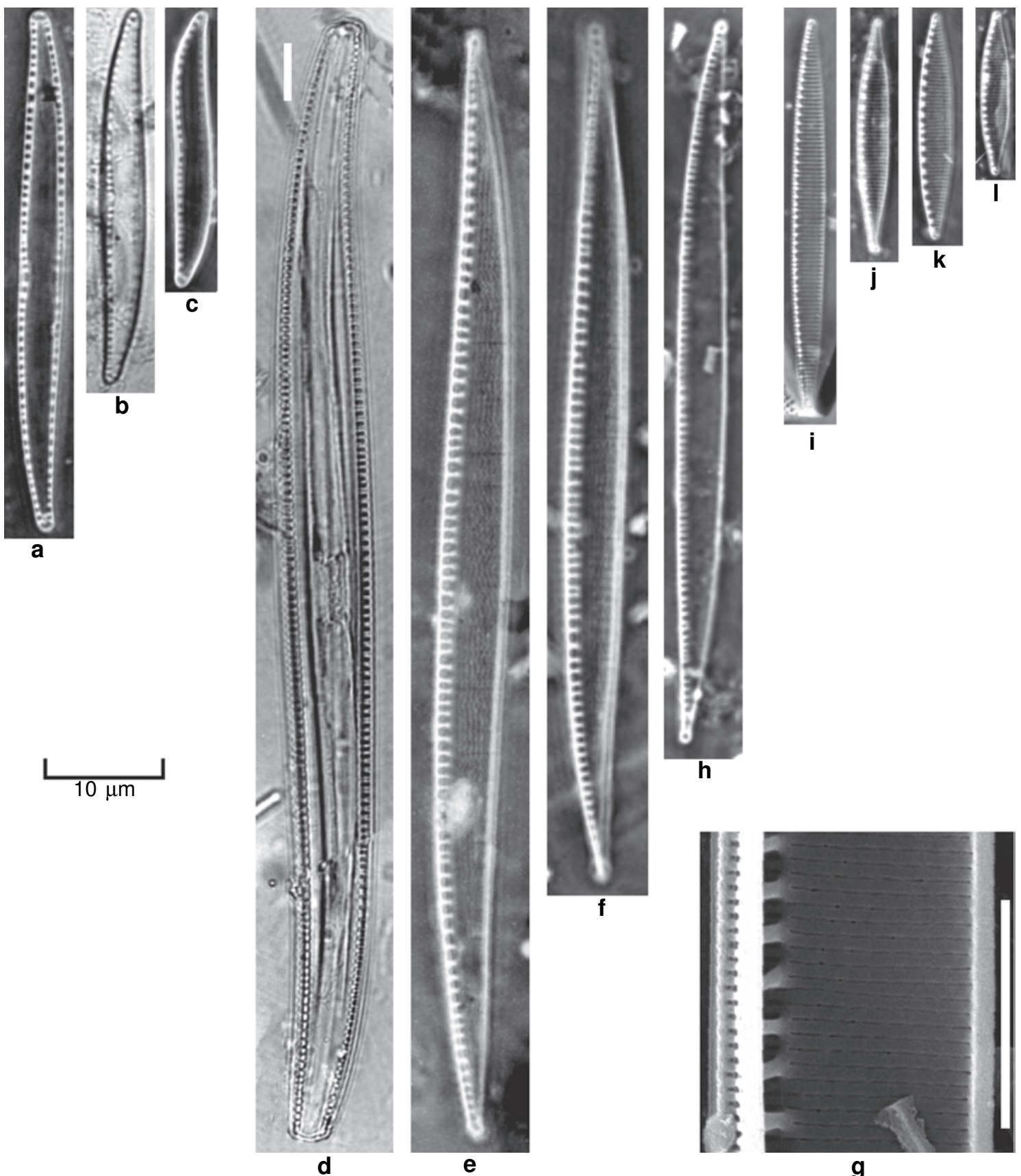

d

e

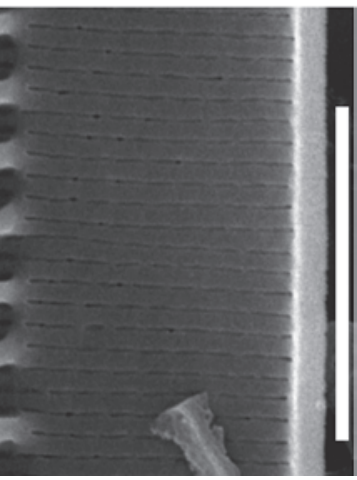

g

Figura 9 - MO e MEV - a-c. N. scalpelliformis. d-h. N. sigma, MEV: h. Detalhe da região central da valva, vista interna. i-1. N. solita. Escalas $=10 \mu \mathrm{m} ; \mathrm{h}=3 \mu \mathrm{m}$.

Figura 9 - LM and SEM - a-c. N. scalpelliformis. d-h. N. sigma, SEM: h. Detail of the valve's central area, internal view. i-1. N. solita. Scale bars $=10 \mu \mathrm{m}, \mathrm{h}=3 \mu \mathrm{m}$.

32. Nitzschia subacicularis Hust. in Schmidt's Atlas, pl. 348: 76. 1874-1959.

Fig. 10 a-i

Valvas linear-lanceoladas, extremidades atenuado-apiculadas, fíbulas equidistantes, estrias nitidamente pontuadas. Medidas: $18-49 \mu \mathrm{m}$ de comprimento; 2-3 $\mu \mathrm{m}$ de largura, 11-15 fíbulas em $10 \mu \mathrm{m}, 30-34$ estrias em $10 \mu \mathrm{m}$.

Lâminas examinadas: 5771, 5773, 5779, 5783, 5785, 5789, 5792, 5808, 5809, 5811, 5813, 5814, 5846, 5973, 5892, 5893, 5980, 5983, 5999, 6004, 6016, 6018, 6023. 
Os espécimes observados concordam com a ilustração do material tipo de Hustedt em Schmidt et al. (1874-1959). Este táxon foi descrito com base em material encontrado em Sphagnum L. nas Ilhas Sumatra, Indonésia (Hustedt 1938), com valores de 30-42 $\mu \mathrm{m}$ de comprimento, $2,5 \mu \mathrm{m}$ de largura, 14-16 fíbulas em $10 \mu \mathrm{m}$ e cerca de 33 estrias em $10 \mathrm{~mm}$. Krammer \& Lange-Bertalot (1988) ampliaram estas dimensões: $20-80 \mu \mathrm{m}$ de comprimento, $2-3 \mu \mathrm{m}$ de largura, 12-16 fíbulas em $10 \mu \mathrm{m}$ e 2633 estrias em 10 mm. Primeira citação para o Rio Grande do Sul.

33. Nitzschia subcohaerens (Grun.) Van Heurck var. scotica Grun in Van Heurck, A Treatise on the Diatomaceae, p. 406, fig. 127. $1896 . \quad$ Fig. 10 j-m

Valvas linear-lanceoladas, extremidades levemente atenuadas, levemente curvadas para sentidos opostos, fíbulas não equidistantes interrompidas por maior espaçamento na região central, estrias inconspícuas em MO. Em MEV, observam-se estrias formadas por uma fileira de aréolas e fíbulas de tamanhos desiguais (Fig. $10 \mathrm{j}$ ). Medidas: 42-57 $\mu \mathrm{m}$ de comprimento, 4-5 $\mu \mathrm{m}$ de largura, 8-10 fíbulas em $10 \mu \mathrm{m}, 30-33$ estrias em $10 \mu \mathrm{m}$.

Lâminas examinadas: 5737, 5771, 5779, 5789, 5809, 5811, 5980, 5983, 5893, 5894, 6004, 5997, 5999.

Os exemplares encontrados conferem com as medidas e morfologia apresentada por Krammer \& Lange-Bertalot (1988). Assemelha-se a N. filiformis var. conferta, mas difere desta no formato valvar e na disposição da rafe. Segundo Krammer \& LangeBertalot (1988) a var. scotica é possivelmente cosmopolita, tendo sua origem em águas salobras de zonas costeiras. Também foi encontrada por Witkanski et al. (2000), em ambientes marinhos. Nas amostras analisadas foram encontrados indivíduos com plastos viáveis.

34. Nitzschia tubicola Grun. in Cleve \& Grunow, K. Svenska Vet.-Akad., Handl. ser. 4, 17(2): 97. 1880.

Fig. 10 n-o

Valvas lineares a linear-lanceoladas levemente constritas no centro, extremidades cuneadas subcapitado-rostradas, fíbulas equidistantes interrompidas por maior espaçamento na região central, estrias inconspícuas em MO. Medidas: 23-39 $\mu \mathrm{m}$ de comprimento, 3-4 $\mu$ m delargura, 12-14 fibulas em $10 \mu \mathrm{m}$. Lâminas examinadas: 5737, 5771, 5779, 5780, 5785, 5792, 5816, 5845, 6004.

Apesar de os valores métricos concordarem com os apresentados por Krammer \& Lange-Bertalot (1988) para a flora da Europa, morfologicamente, os indivíduos estudados assemelham-se somente a alguns indivíduos ilustrados por estes autores (pl. 64 , figs 15,16 ).

35. Nitzschia vermicularis (Kütz.) Hantzsch in Rabenhorst, Alg. Sachsens 89/90: 889. 1859.

Fig. 10 p-r

Valvas lineares, extremidades atenuadas levemente rostradas, fíbulas alongadas não equidistantes, estrias inconspícuas em MO. Medidas: $135-155 \mu \mathrm{m}$ de comprimento, 6-7 $\mu \mathrm{m}$ de largura, 7-9 fíbulas em $10 \mu \mathrm{m}$.

Lâminas examinadas: 5772, 5779, 5785, 5809, 5844, 5973, 5980, 5983, 5997, 6016, 6022, 6023.

Os organismos observados conferem métrica e morfologicamente com os encontrados por Krammer \& Lange-Bertalot (1988) na flora da Europa. Esta espécie difere de $N$. vermicularioides Lange-Bert, pois esta apresenta maior densidade de fíbulas em $10 \mu \mathrm{m}$ (12-14). Na América do sul, $N$. vermicularis foi encontrada no Chile por Rumrich et al. (2000). No Rio Grande do Sul, foi registrada para o Lago Guaiba e citada para as áreas úmidas do litoras sul (Torgan et al.1999).

\section{Riqueza e distribuição dos táxons}

O gênero Nitzschia esteve bem representado nos ambientes lacustres estudados na Planície Costeira do Rio Grande do Sul. Com relação às duas áreas de estudo, a área da Lagoa do Casamento apresentou maior riqueza (35 táxons) em relação à área do Butiazal de Tapes (13 táxons) (Fig. 11).

A distribuição dos táxons na área da Lagoa do Casamento, entretanto, não foi homogênea (Fig. 11). Alguns ambientes como lagoas dos Gateados norte e sul, banhado entre a lagoa do Casamento e Capivari e banhado Rincão do Anastácio apresentaram maior número de táxons (>21 táxons), em relação aos demais ambientes, enquanto que na lagoa Capivari e no banhado Ilha Grande, os números de espécies encontradas foram bem menores (um e treze táxons, respectivamente).

$\mathrm{Na}$ área do Butiazal de Tapes também houve variação na distribuição dos táxons (Fig. 11). O açude da Fazenda São Miguel apresentou maior riqueza (10 táxons) enquanto que o banhado com Sphagnum L. foi o que demonstrou a menor riqueza (dois táxons).

A maior riqueza de representantes de Nitzschia na área da Lagoa do Casamento deve-se a presença exclusiva nesta área de 22 táxons, a saber: Nitzschia agnita, N. brevissima var. brevissima, N. brevissima var. terricola, N. bryophila, N. clausii, N. dissipata var. borneensis, $N$. cf. epiphytica, $N$. frequens, $N$. latens, 

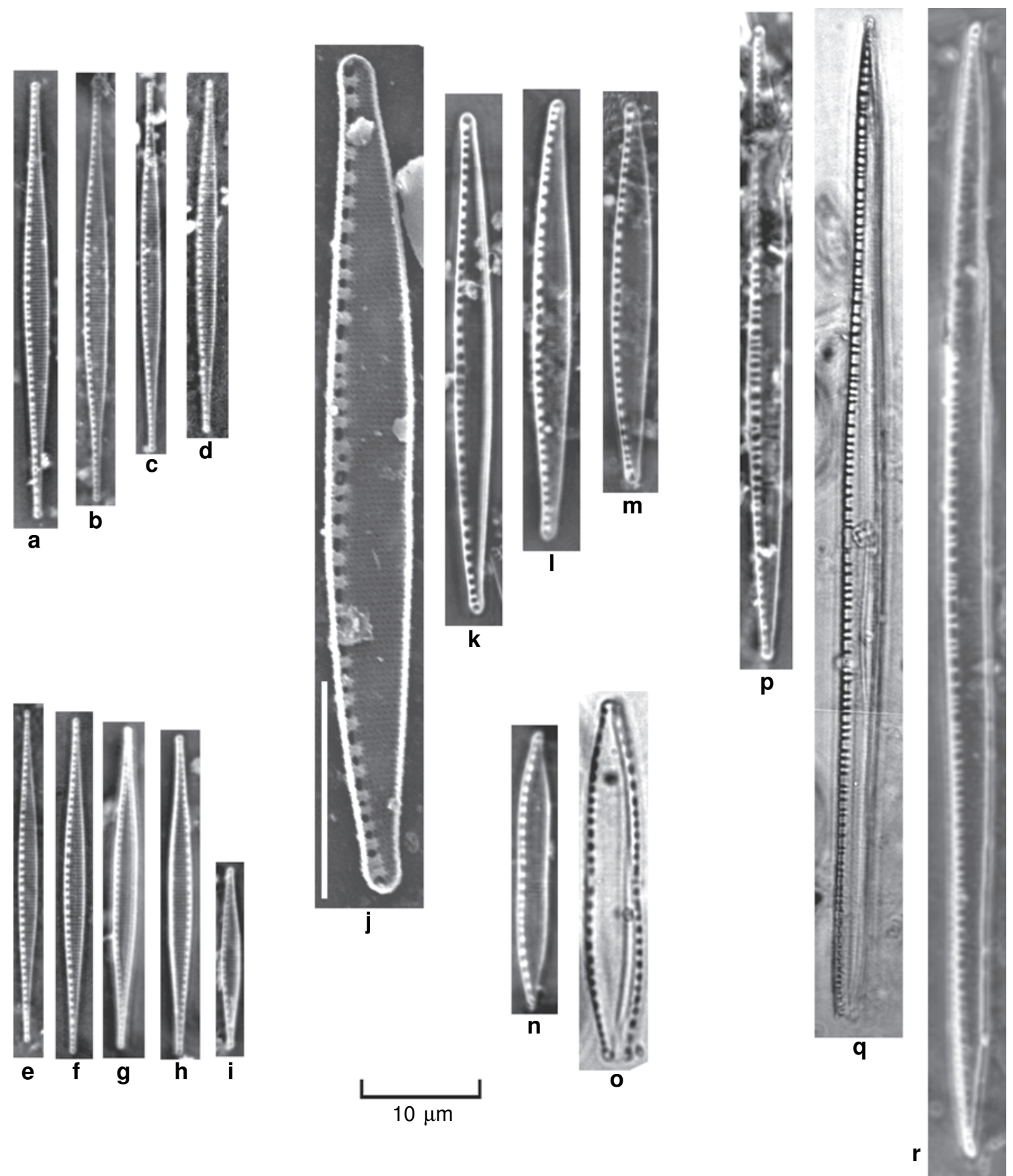

$10 \mu \mathrm{m}$

apresentou ocorrência restrita à área do Butiazal de Tapes (Tab. 3).

Um total de 13 táxons esteve presente nas duas $N$. rautenbachiae, $N$. reversa, $N$. rostellata, $N$. scalaris, $N$. scalpelliformis, N. solita, N. subacicularis, $N$. vermicularis, enquanto nenhuma espécie áreas de estudo: $N$. acicularis var. major, $N$. dissipata 

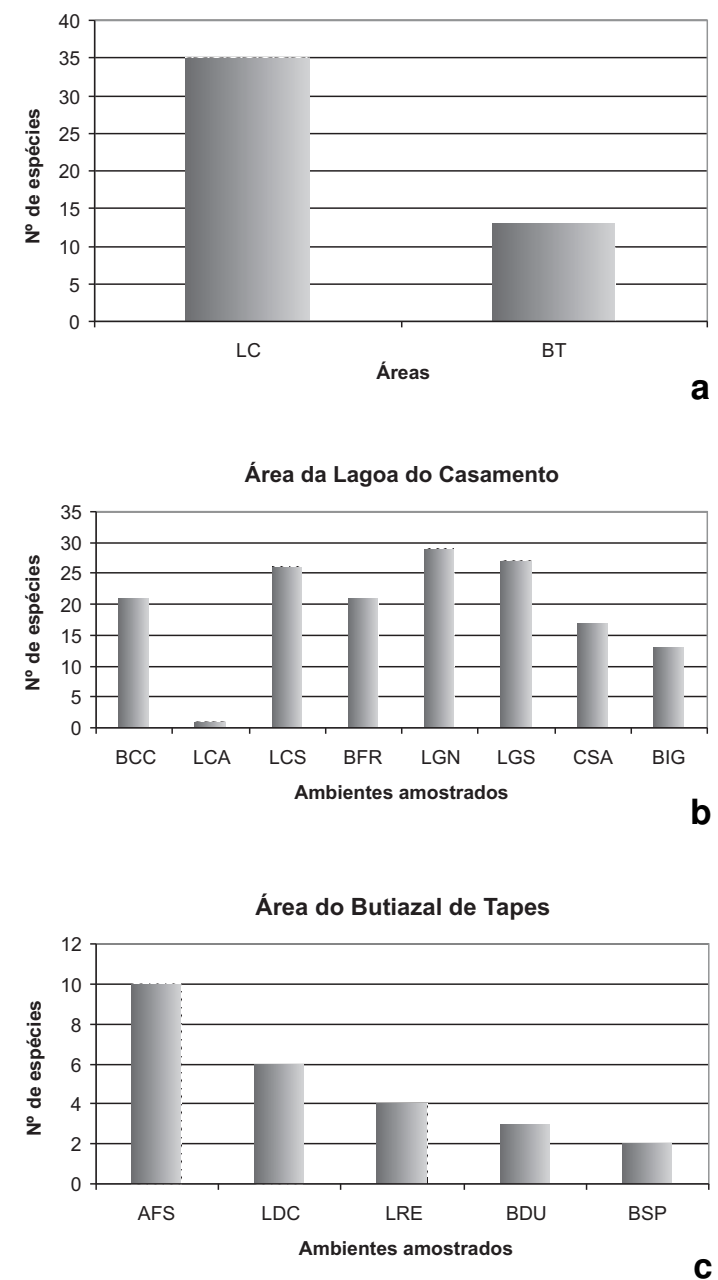

Figura 11 - a. Riqueza de espécies nas áreas da Lagoa do Casamento (LC) e Butiazal de Tapes (BT). b. Riqueza de espécies nos ambientes da área da Lagoa do Casamento. c. Riqueza de espécies nos ambientes da área do Butiazal de Tapes. $\mathrm{BCC}=$ banhado entre lagoas do Casamento e Capivari, LCA = lagoa Capivari, $\mathrm{LCS}=$ lagoa do Casamento, $\mathrm{BFR}=$ banhado fazenda Rincão do Anastácio, LGN = lagoa dos Gateados - norte, LGS = lagoa dos Gateados - sul, CSA = canal Sangradouro, $\mathrm{BIG}=$ banhado Ilha Grande, $\mathrm{AFS}=$ açude fazenda São Miguel, LDC = lagoa das Capivaras, LRE = lagoa Redonda, $\mathrm{BDU}=$ banhado entre dunas, $\mathrm{BSP}=$ banhado com Sphagnum, LCH - lagoa Charutão.

Figura 11 - a. Species richness in the Lagoa do Casamento (LC) and Butiazal de Tapes (BT) areas. b. Species richness in the environments of the Lagoa do Casamento area. c. Species richness in the environments of Butiazal de Tapes area. Areas: $\mathrm{BCC}=$ swamp between Casamento and Capivari lakes, LCA = Capivari lake, LCS = Casamento lake, BFR $=$ swamp of Rincão do Anastácio Farm, $\mathrm{LGN}=$ North Gateados lake, LGS $=$ South Gateados lake, CSA = Sangradouro channel, BIG $=$ Ilha Grande swamp, AFS = pond of São Miguel's farm, LDC = Capivara lake, $\mathrm{LRE}=$ Redonda lake, $\mathrm{BDU}=$ between dunes swamp, $\mathrm{BSP}=$ Sphagnum swamp, $\mathrm{LCH}=$ Charutão lake. var.?, N. gracilis, N. intermedia, N. linearis var. linearis, $N$. nana, $N$. palea var. palea, $N$. palea var. debilis, N. pseudofonticola, N. pumilum, $N$. sigma, N. subcohaerens var. scotica e N. tubicola (Tab. 3).

A distinção entre as duas áreas de estudo torna-se bastante evidente quando se examina o resultado da Análise de Espécies Indicadoras de Dupla Entrada (TWINSPAN) (Fig. 12). No primeiro nível de corte do agrupamento, observa-se na dicotomia fundamental, a distinção de dois grandes grupos em função da presença exclusiva de $N$. clausii nas amostras situadas à esquerda da partição. Em sua maioria, estes ambientes compõem a área da lagoa do Casamento, exceção feita à lagoa Capivari e banhado Ilha Grande, agrupados à direita. Logo no segundo nível dá-se a resolução definitiva da classificação com o conseqüente isolamento das unidades amostrais da área do Butizial de Tapes, formando-se assim quatro grupos com associações de táxons distintos, situação que denota a existência de gradiente abiótico determinando a distribuição das espécies de Nitzschia ao longo dos ambientes lacustres.

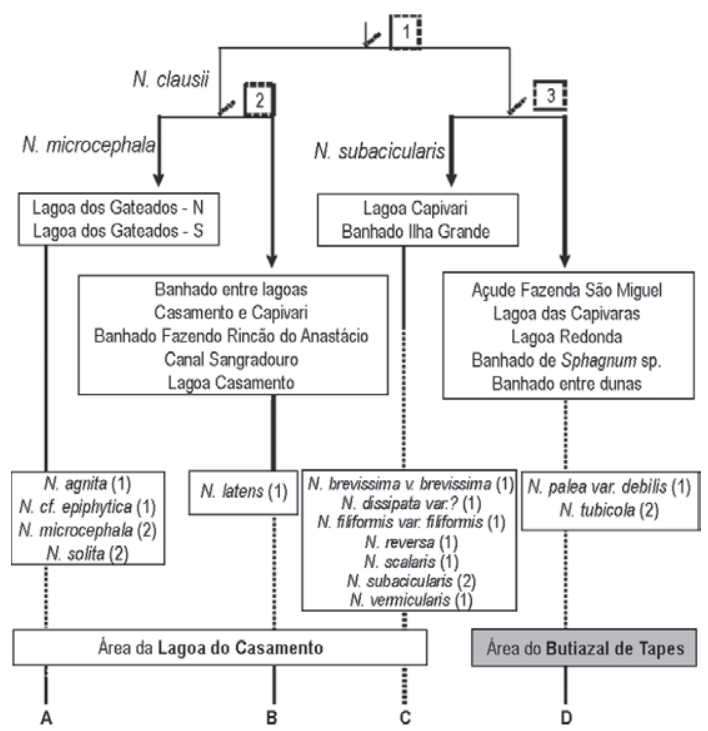

Figura 12-Análise de Espécies Indicadoras (TWINSPAN). Os ambientes e as espécies de ocorrência exclusiva associadas a cada grupo (A, B, C e D), estão indicados no interior dos quadrados. Os números entre parênteses indicam a frequência de ocorrência da espécie no grupo.

Figure 12 - Indicator Species Analysis (TWINSPAN). The environments and exclusive occurrence species associated to each group (A,B,C,D), are indicated inside the squares. The numbers in brackets indicate the species occurrence frequency in the group. 
Tabela 3 - Distribuição das espécies de Nitzschia nos ambientes lacustres das áreas da Lagoa do Casamento e Butiazal de Tapes. $\mathrm{P}=$ plâncton, $\mathrm{M}=$ metafíton, $\mathrm{BCC}=$ banhado entre lagoas do Casamento e Capivari, $\mathrm{LCA}=$ lagoa Capivari, LCS= lagoa do Casamento, BFR= banhado fazenda Rincão do Anastácio, LGN = lagoa dos Gateados norte, LGS = lagoa dos Gateados - sul, CSA = canal Sangradouro, BIG = banhado Ilha Grande, AFS = açude fazenda São Miguel, LDC = lagoa das Capivaras, $\mathrm{LRE}=$ lagoa Redonda, $\mathrm{BDU}=$ banhado entre dunas, $\mathrm{BSP}=$ banhado com Sphagnum, LCH = lagoa Charutão.

Table 3 - Nitzschia species distribution in lacustrine environment of the Lagoa do Casamento and Butiazal de Tapes. $\mathrm{P}=$ plankton, $\mathrm{M}=$ metaphyton. Areas: $\mathrm{BCC}=$ swamp between Casamento and Capivari lakes, $\mathrm{LCA}=$ Capivari lake, LCS $=$ Casamento lake, BFR = swamp of Rincão do Anastácio Farm, LGN = North Gateados lake, LGS = South Gateados lake, CSA = Sangradouro channel, BIG = Ilha Grande swamp, AFS = pond of São Miguel's farm, LDC = Capivara lake, $\mathrm{LRE}=$ Redonda lake, $\mathrm{BDU}=$ between dunes swamp, $\mathrm{BSP}=$ Sphagnum swamp, $\mathrm{LCH}=$ Charutão lake.

\begin{tabular}{|c|c|c|c|c|c|c|c|c|c|c|c|c|c|}
\hline \multirow[b]{2}{*}{ Espécies } & \multirow[b]{2}{*}{ B C C } & \multirow[b]{2}{*}{ LCA } & \multicolumn{6}{|c|}{ Área da Lagoa do Casamento } & \multicolumn{5}{|c|}{ Área do Butiazal de Tapes } \\
\hline & & & LCS & BFR & LGN & LGS & CSA & B IG & AFS & LDC & LRE & BDU & BSP \\
\hline N. acicularis v. major & $\mathrm{P}$ & - & - & M & - & - & - & - & M & - & - & - & - \\
\hline N. agnita & - & - & - & - & - & M & - & - & - & - & - & - & - \\
\hline N. brevissima v. brevissima & $\mathrm{P}-\mathrm{M}$ & - & $\mathrm{P}-\mathrm{M}$ & - & $\mathrm{P}-\mathrm{M}$ & $\mathrm{P}$ & $\mathrm{P}-\mathrm{M}$ & $\mathrm{P}-\mathrm{M}$ & - & - & - & - & - \\
\hline N. brevissima aff. v. terricola & $\mathrm{P}$ & - & - & M & M & - & - & - & - & - & - & - & - \\
\hline N. bryophila & - & - & M & - & $\mathrm{P}-\mathrm{M}$ & M & - & - & - & - & - & - & - \\
\hline N. clausii & $\mathrm{P}-\mathrm{M}$ & - & $\mathrm{P}-\mathrm{M}$ & M & $\mathrm{P}-\mathrm{M}$ & $\mathrm{P}$ & $\mathrm{P}-\mathrm{M}$ & - & - & - & - & - & - \\
\hline N. dissipata $v$. borneensis & - & - & $\mathrm{P}$ & - & - & M & - & - & - & - & - & - & - \\
\hline N. dissipata v.? & - & - & $\mathrm{P}$ & M & M & M & M & - & - & - & M & M & - \\
\hline N.cf. epiphytica & - & - & - & - & - & M & - & - & - & - & - & - & - \\
\hline N. filiformis v. filiformis & $\mathrm{P}-\mathrm{M}$ & - & $\mathrm{P}$ & - & $\mathrm{P}-\mathrm{M}$ & M & $\mathrm{M}$ & M & - & - & - & - & - \\
\hline N. filiformis v. conferta & - & - & M & $\mathrm{P}-\mathrm{M}$ & M & M & - & - & - & - & - & - & - \\
\hline$N$. cf. frequens & - & - & $\mathrm{P}$ & $\mathrm{P}-\mathrm{M}$ & M & $\mathrm{P}-\mathrm{M}$ & - & - & - & - & - & - & - \\
\hline N. gracilis & $\mathrm{P}-\mathrm{M}$ & - & $\mathrm{P}-\mathrm{M}$ & - & $\mathrm{P}-\mathrm{M}$ & $\mathrm{P}-\mathrm{M}$ & $\mathrm{P}-\mathrm{M}$ & $\mathrm{P}-\mathrm{M}$ & $\mathrm{P}-\mathrm{M}$ & $\mathrm{P}-\mathrm{M}$ & - & - & - \\
\hline N. intermedia & $\mathrm{P}-\mathrm{M}$ & - & $\mathrm{P}-\mathrm{M}$ & $\mathrm{P}-\mathrm{M}$ & $\mathrm{P}-\mathrm{M}$ & $\mathrm{P}-\mathrm{M}$ & $\mathrm{P}-\mathrm{M}$ & $\mathrm{P}$ & $\mathrm{P}-\mathrm{M}$ & - & - & $\mathrm{M}$ & - \\
\hline N. latens & $\mathrm{P}$ & - & $\mathrm{P}-\mathrm{M}$ & - & - & - & - & - & - & - & - & - & - \\
\hline N. linearis v. linearis & $\mathrm{P}-\mathrm{M}$ & - & $\mathrm{P}-\mathrm{M}$ & $\mathrm{P}-\mathrm{M}$ & $\mathrm{P}-\mathrm{M}$ & $\mathrm{P}-\mathrm{M}$ & M & $\mathrm{P}-\mathrm{M}$ & $\mathrm{P}-\mathrm{M}$ & - & - & - & - \\
\hline$N$. linearis v. tenuis & - & - & - & - & M & - & - & - & - & - & - & - & - \\
\hline N. lorenziana & - & - & $\mathrm{P}-\mathrm{M}$ & - & $\mathrm{P}-\mathrm{M}$ & - & - & - & - & - & - & - & - \\
\hline N. microcephala & - & - & $\mathrm{P}$ & - & M & M & - & - & - & - & - & - & - \\
\hline N. nana & $\mathrm{P}-\mathrm{M}$ & - & $\mathrm{P}-\mathrm{M}$ & M & $\mathrm{P}-\mathrm{M}$ & $\mathrm{P}-\mathrm{M}$ & - & $\mathrm{P}-\mathrm{M}$ & $\mathrm{P}-\mathrm{M}$ & M & - & - & - \\
\hline N. palea v. palea & $\mathrm{P}-\mathrm{M}$ & $\mathrm{P}$ & $\mathrm{P}-\mathrm{M}$ & $\mathrm{P}-\mathrm{M}$ & $\mathrm{P}-\mathrm{M}$ & $\mathrm{P}-\mathrm{M}$ & $\mathrm{P}-\mathrm{M}$ & $\mathrm{P}-\mathrm{M}$ & $\mathrm{P}-\mathrm{M}$ & M & $\mathrm{M}$ & $\mathrm{M}$ & M \\
\hline N. palea v. debilis & $\mathrm{P}$ & - & $\mathrm{P}$ & $\mathrm{P}-\mathrm{M}$ & $\mathrm{P}-\mathrm{M}$ & - & - & - & $\mathrm{P}-\mathrm{M}$ & - & - & - & - \\
\hline N. pseudofonticola & $\mathrm{P}-\mathrm{M}$ & - & $\mathrm{P}-\mathrm{M}$ & $\mathrm{P}-\mathrm{M}$ & $\mathrm{P}-\mathrm{M}$ & $\mathrm{P}-\mathrm{M}$ & $\mathrm{P}-\mathrm{M}$ & - & M & M & M & - & - \\
\hline N. pumila & - & - & $\mathrm{P}-\mathrm{M}$ & P-M & M & $\mathrm{P}-\mathrm{M}$ & M & $\mathrm{P}$ & - & - & - & - & M \\
\hline N. rautenbachiae & - & - & - & - & - & $\mathrm{P}-\mathrm{M}$ & $\mathrm{P}$ & - & - & - & - & - & - \\
\hline$N$. reversa & $\mathrm{P}-\mathrm{M}$ & - & $\mathrm{P}$ & M & $\mathrm{P}-\mathrm{M}$ & $\mathrm{P}$ & M & M & - & - & - & - & - \\
\hline N. rostellata & $\mathrm{P}$ & - & - & M & M & - & - & - & - & - & - & - & - \\
\hline N. scallaris & - & - & M & $\mathrm{P}-\mathrm{M}$ & M & - & $\mathrm{P}$ & $\mathrm{P}$ & - & - & - & - & - \\
\hline N. scalpelliformis & $\mathrm{P}-\mathrm{M}$ & - & $\mathrm{P}-\mathrm{M}$ & M & $\mathrm{P}-\mathrm{M}$ & M & M & - & - & - & - & - & - \\
\hline N. sigma & $\mathrm{P}-\mathrm{M}$ & - & $\mathrm{P}$ & $\mathrm{P}-\mathrm{M}$ & $\mathrm{P}-\mathrm{M}$ & $\mathrm{P}-\mathrm{M}$ & $\mathrm{M}$ & $\mathrm{P}$ & $\mathrm{P}-\mathrm{M}$ & M & $\mathrm{M}$ & - & - \\
\hline N. solita & - & - & - & - & M & M & - & - & - & - & - & - & - \\
\hline N. subacicularis & $\mathrm{P}-\mathrm{M}$ & - & $\mathrm{P}$ & $\mathrm{P}-\mathrm{M}$ & $\mathrm{P}-\mathrm{M}$ & $\mathrm{P}-\mathrm{M}$ & $\mathrm{P}$ & M & - & M & - & - & - \\
\hline N. subcohaerens v. scotica & $\mathrm{P}-\mathrm{M}$ & - & $\mathrm{P}$ & $\mathrm{P}-\mathrm{M}$ & M & $\mathrm{P}-\mathrm{M}$ & $\mathrm{P}$ & - & - & - & - & - & - \\
\hline N. tubicola & $\mathrm{P}$ & - & - & - & $\mathrm{P}-\mathrm{M}$ & $\mathrm{P}-\mathrm{M}$ & - & - & $\mathrm{P}-\mathrm{M}$ & - & - & - & - \\
\hline N. vermicularis & M & - & $\mathrm{P}-\mathrm{M}$ & M & $\mathrm{P}-\mathrm{M}$ & $\mathrm{P}-\mathrm{M}$ & - & $\mathrm{P}-\mathrm{M}$ & - & - & - & - & - \\
\hline TOTAL & 21 & 1 & 26 & 21 & 29 & 27 & 17 & 13 & 10 & 6 & 4 & 3 & 2 \\
\hline
\end{tabular}


A separação nítida entre as áreas da Lagoa do Casamento e Butiazal de Tapes, com base nas espécies indicadoras, pode ser explicada pelos tipos de ambientes lacustres associados as suas condições abióticas. Na área da lagoa do Casamento, as lagoas interligadas (lagoa do Casamento, lagoa Capivari, lagoas dos Gateados - norte e sul) e banhados adjacentes (banhado entre lagoa do Casamento e lagoa Capivari) detiveram maior riqueza e grupo de espécies (grupos A, B e C), possivelmente devido à conexão destes ambientes com a laguna dos Patos, a qual detém uma flora rica de representantes do gênero Nitzschia (Torgan 1997). Por outro lado, os maiores valores de condutividade encontrado nas águas da área da Lagoa do Casamento (80-382 $\left.\mu \mathrm{S} \mathrm{cm}^{-1}\right)$ em relação as da área do Butiazal de Tapes $\left(12-70 \mu \mathrm{S} \mathrm{cm}^{-1}\right)$ e os valores mais baixos de $\mathrm{pH}$ encontrados nas lagoas isoladas e banhados entre dunas da área do Butiazal de Tapes (5,0-6,3), comparativamente aos ambientes da área da Lagoa do Casamento $(6,1-7,4)$, podem ser a causa da menor riqueza do gênero, observada na área do Butiazal de Tapes. Nitzschia é reconhecidamente um gênero cujos representantes são preferencialmente encontrados em águas neutras e básicas, com alta condutividade e que toleram altas concentrações de matéria orgânica, sendo indicadoras de condições meso á-polissapróbicas (Hustedt 1937-1938; Slàdecek 1973; Cox 1996).

Quanto ao hábito, a maioria dos táxons $(91 \%)$ ocorreu no plâncton e metafíton, sendo que somente 9\% das espécies restringiram-se ao metafíton, foram elas: N. brevissima var. brevissima, N. cf. epiphytica, N. linearis var. tenuis e $N$. solita (Tab. 3). N. palea se destacou como táxon de distribuição mais ampla estando presente tanto no plâncton como metafíton, em todos os ambientes das áreas de estudo, exceção feita à lagoa do Charutão.

Destaca-se ainda, 11 novas ocorrências para o estado: $N$. acicularis var. major, $N$. dissipata var. borneensis, $N$. latens, $N$. linearis var. tenuis, $N$. pseudofonticola, $N$. rautenbachiae, $N$. solita, $N$. subcohaerens var. scotica, $N$. subacicularis e $N$. tubicola. Para a Planície Costeira do Rio Grande do Sul, N. agnita, N. brevissima var. brevissima e var. terricola, $N$. filiformis var. conferta e $N$. rostellata, são pela primeira vez referidas.

\section{Agradecimentos}

As autoras agradecem ao Conselho Nacional de Desenvolvimento Científico e Tecnológico CNPq as bolsas de Mestrado e Produtividade em Pesquisa, concedidas à primeira e à segunda autora, respectivamente. Ao Centro de Geoprocessamento do Museu de Ciências Naturais, Fundação Zoobotânica do Rio Grande do Sul e ao Centro de Microscopia Eletrônica da Universidade Federal do Rio Grande do Sul o auxílio prestado. À Prof ${ }^{a} \operatorname{Dr}^{a}$ Marinês Garcia (UFPel), Prof ${ }^{a} \mathrm{Dr}^{\mathrm{a}}$ Thelma A. Ludwig (UFPR) e Prof ${ }^{\mathrm{a}} \mathrm{Dr}^{\mathrm{a}}$ Luciana Cardoso (UFRGS) as valiosas contribuições ao trabalho. À Msc. Fabiana Schneck e Msc. Guilherme Hermany o auxílio na análise estatística. À Cristiane Bahi dos Santos o apoio técnico com bolsa do CNPq.

\section{Referências}

Bicudo, C.M.E. \& Bicudo, T.R. 1970. Alga de águas continentais brasileiras. Editora da USP, São Paulo. 228p.

Buselato, T.C. \& Aguiar, L. 1979. Diatomáceas do Rio Mampituba, Torres, Rio Grande do Sul, Brasil. Iheringia, Série Botânica 24: 91-123.

Callegaro, V.L.M. 1981. Estudo das comunidades fitoplanctônicas da Lagoa Negra, Parque Estadual de Itapuã, Rio Grande do Sul, Brasil. Iheringia, Série Botânica 28: 157-167.

Callegaro, V.L.M. \& Salomoni, S.E. 1988. Diatomáceas das lagoas do Jacaré, do Nicola e Mangueira, Estação Ecológica do Taim: novas ocorrências para o Rio Grande do Sul. Iheringia, Série Botânica 38: 127-148.

Cardoso, L.S. \& Motta Marques, D.M.L. 2003. Rate of change of phytoplankton community in Itapeva lake (North Coast of Rio Grande do Sul - Brazil), based on the wind driven hydrodynamic regime. Hydrobiologia 497: 1-12.

Cardoso, L.S. \& Motta Marques, D.M.L. 2004. Seazonal composition of the phytoplankton community in Itapeva lake (North Coast of Rio Grande do Sul Brazil), in function of hydrodynamic aspects. Acta Limnológica Brasilica 16: 401-416.

Cox, E.J. 1996. Identification of freshwater diatoms from live material. Chapman \& Hall, London. 158p.

Garcia, M. \& Vélez, E. 1995. Algas planctônicas da Lagoa Emboaba, planície costeira no Rio Grande do Sul, Brasil: avaliação quantitativa. Boletim do Instituto de Biociências 54: 75-114.

Germain, H. 1981. Flore des Diatomées. Société Nouvelle des Éditions Boubée, Paris.

Guermeur, P. 1954. Diatomées de L'A. O. F. (première liste : Sénégal). Institut Français D’A Arique Noire. 137p.

Guiry, M.D. \& Guiry, G.M. 2010. AlgaeBase. Worldwide electronic publication, National University of Ireland, Galway. Disponível em <http://www. algaebase.org $>$. Acesso em 19 maio 2010.

Hartley, B. (org.). 1996. An atlas of British diatoms. Biopress, Bristol. 120p.

Hill, M.O. 1979. Twinspan - A Fortran program for arranging multivariate data in an ordered two-way table by classification of the individuals and atributes. Cornell University, Ithaca. 60p. 
Hustedt, F. 1930. Bacillariophyta (Diatomeas). In: Pascher, A. (ed.). Die Süsswasser-Flora Mitteleuropas. Vol. 10. Gustav Fischer Verlag, Jena. Pp. 1-466.

Hustedt, F. 1937-8. Systematische und Okologische Untersuchungen über de Diatomeen-Flora von Java, Bali und Sumatra. Archive für Hydrobiologie 15: 131-505.

Hustedt, F. 1943. Neue und wenig bekannte Diatomeen. Bericht der Deutschen botanischen Gesellschaft 61: 271-290.

Hustedt, F. 1949. Susswasser-Diatomeen aus der AlbertNationalpark in Belgisch Kongo. M. Hayez, Bruxelles. 199p.

Hustedt, F. 1957. Die Diatomeenflora des Fluss-systems der Weser im Gebiet der Hansestadt Bremen. Abhandlungen vom Naturwissenschaftlichen Verein zu Bremen 34: 181-440.

Krammer, K. \& Lange-Bertalot, H. 1988. Bacillariophyceae. Teil 2: Bacillariaceae, Epithemiaceae, Surirellaceae. In: Ettl, H.; Gerloff, J.; Heyning, H. \& Mollenhauer, D. (eds.). Süßwasserflora von Mitteleuropa. Gustav Fisher Verlag, Stuttgart. 596p.

Lange-Bertalot, H. \& Metzeltin, D. 1996. Indicators of oligotrophy. In: Lange-Bertalot, H. (ed.). EcologyDiversity-Taxonomy. Vol. 2. Iconographia diatomologica Koeltz Scientific Books. 390p.

Lange-Bertalot, H. \& Simonsen, R. 1978. A taxonomic revision of the Nitzschiae lanceolatae Grunow. 2. European and related extra-European freshwater and brackish water taxa. Bacillaria 1: 11-112.

Lobo, E.A.; Tatsch, D.B.; Schuler, S. \& Neves, M.T. 1994. Limnologia de áreas inundáveis da Planície Costeira do Rio Grande do Sul, Brasil, onde ocorrem espécies de anatídeos com valor cinegético. Caderno de Pesquisa, Série Botânica 6: 25-73.

Lobo, E.A.; Callegaro, V.L.M.; Wetzel, C.E.; Hermany, G. \& Bes, D. 2004a. Water quality study of the Condor and Capivara streams, Porto Alegre municipal district, RS, Brazil, using epilithic diatoms biocenoses as bioindicators. Oceanological and Hydrobiological Studies 2: 77-93.

Lobo, E.A.; Bes, D.; Tudesque, L. \& Ector, L. 2004b. Water quality study of Pardinho River, RS, Brazil, using epilithic diatoms assemblages and faecal coliforms as biological indicators. Vie et Milieu 54: 115-136.

Ludwig, T. 1989. Uma nova combinação, a nível varietal, do gênero Nitzschia Hassall. (Chrysophyta, Bacillariophyta). Estudos de Biologia 20: 3-5.

Mayer, A. 1913. Die Bacillariaceen der Regensburger Gewässer. Berichte des naturwissenschaftlichen (früher zoologisch-mineralogischen) vereines $\mathrm{u}$ Regensburg. Heft XIV. Allgemeiner Teil, 50 S.; Systematischer Teil, 364 S. 30Pl.

McCune, B. \& Mefford, M.J. 1999. PC-ORD version 4.0. Multivariate analysis of ecological data: users guide. MjM Software Design, Glaneden Beach. 237p.
Metzeltin, D. \& Lange-Bertalot, H. 1998. Tropical diatoms of South America I. Diversity-TaxonomyGeobotany. In: Lange-Bertalot, H. (ed.). Iconographia diatomologica. Vol. 5. Koeltz Scientific Books, Gantner Verlag, Königstein. 695p.

Metzeltin, D.; Lange-Bertalot, H. \& García-Rodríguez, F. 2005. Diatoms of Uruguay. In: Lange-Bertalot, H. (ed.). Iconographia diatomologica. Vol. 15. Koeltz Scientific Books, Gantner Verlag, Königstein. 736p.

Moreira-Filho, H.; Valente-Moreira, I.M. \& SouzaMossimann, R.M. 1985. Catálago das diatomáceas (Chrysophyta-Bacillariphyceae) marinhas e estuarinas do estado de Santa Catarina, Brasil. Ínsula 15: 33-85.

Müller, O. 1909. Bacillariaceen aus Südpatagonien. (Engler's) Botaniche Jahrbücher für Systematik, Pflazanzengegeschichte und Pflanzengeographie 43: $1-40$.

Oliveira, M.A.; Torgan, L.C.; Lobo, E.A. \& Schwarzbold, A. 2001. Associations of periphytic diatom species of artificial substrate in lotic environments in the arroyo Sampaio Basin, Rio Grande do Sul, Brazil: with abiotic variables. Brazilian Journal of Biology 61: 523-540.

Raupp, S.V.; Torgan, L.C. \& Baptista, L.R.M. 2006. Composição e variação temporal de diatomáceas (Bacillariophyta) no plâncton da represa Canastra, sul do Brasil. Iheringia, Série Botânica 61: 105-138.

Round, F.E.; Crawford, R.M. \& Mann, D.G. 1990. The diatoms: biology \& morphology of the genera. Cambridge University Press, Cambridge. 747p.

Rumrich, U.; Lange-Bertalot, H. \& Rumrich, M. 2000. Diatoms of the Andes. From Venezuela to Patagonia/ Tierra del Fuego. Lange-Bertalot, H. (ed.). Iconographia diatomologica. Vol. 9. Koeltz Scientific Books, Gantner Verlag, Königstein. 673p.

Salomoni, E.S. 1997. Aspectos da limnologia e poluição das Lagoas costeiras Marcelino, Peixoto e Pinguela (Osório, RS): uma abordagem baseada no fitoplâncton. Dissertação de Mestrado. Departamento de Ecologia da Universidade Federal do Rio Grande do Sul, Porto Alegre. 141p.

Schoeman, F.R. \& Archibald, R.E.M. 1966. The diatom flora of Southern Africa. n. 1. Council for Scientific and Industrial Research, Pretoria.

Schmidt, A.; Fricke, F.; Heiden, H.; Müller, O. \& Hustedt, F. 1874-1959. Atlas der Diatomaceen-Kunde. Zentralantiquariat, Leipzig. 1972. Vol. 4. Pp. 387-480.

Simonsen, R. 1974. The diatom plankton of the Indian Ocean expedition of R/V “Meteor" 1964-1965. Meteor Forschungen Ergebnisse. Serie D, 19 Pp. 1-107.

Simonsen, R. 1987. Atlas and catalogue of the diatom types of Friedrich Hustedt. Vol. 1-3. J. Cramer, Berlin. 1741p.

Slàdecek, V. 1973. System of water quality from the biological point of view. Archiv. für Hydrobiologie und Ergebnisse Limnologie 7: 1-218. 
Torgan, L.C.; Becker, V. \& Prates, H.M. 1999. Checklist das diatomáceas (Bacillariophyceae) de ambientes de águas continentais e costeiros do estado do Rio Grande do Sul. Iheringia, Série Botânica 52: 89-144.

Torgan, L.C. 1997. Estrutura e dinâmica da comunidade fitoplanctônica na laguna dos Patos em um ciclo anual. Tese de Doutorado. Universidade Federal de São Carlos, São Paulo. 284p.
Tremarin, P.I; Freire, E.G.O; Bertolli, L.M.O. \& Ludwig, T.A.V. 2009. Catálogo das diatomáceas (OchrophytaDiatomeae) continetais do estado do Paraná. Iheringia, Série Botânica 64: 79-107.

Van Heurck, H. 1880-85. Synopsis des diatomées de Belgique. Anvers. Supl. A, B, C. 235p.

Witkowski, A.; Lange-Bertalot, H. \& Metzeltin, D. 2000. Diatom flora of marine coasts. I. In: Lange-Bertalot, H. (ed.). Iconographia diatomologica. Vol. 7. Koeltz Scientific Books, Ganther Verlang, Königstein. 925p. 